\title{
CAMPANIFORME Y TERRITORIO EN LA CUENCA MEDIA DEL GUADIANA
}

\section{BELL-BEAKER AND TERRITORY IN THE MIDDLE GUADIANA BASIN}

\author{
DANIEL GARCÍA RIVERO ${ }^{1}$
}

Resumen: Se estudia el fenómeno campaniforme en la Cuenca Media del Guadiana con base fundamentalmente en la distribución cerámica y en el análisis de los contextos arqueológicos a niveles macro-territorial y semi-micro. Se realiza una síntesis sobre la historiografía y la problemática en la investigación de este fenómeno a nivel europeo. En contra de la extendida y reconocida acepción funeraria del fenómeno campaniforme a nivel general, en esta región parece relacionarse más bien con usos y procesos de otra índole. Con base en las evidencias actualmente disponibles, puede defenderse el valor restrictivo de prestigio de estas cerámicas y, además, puede proponerse una vinculación estrecha del Campaniforme con estrategias de clientelas políticas promocionadas por parte de los sectores dominantes de estos grupos y comunidades humanas.

Palabras claves: Campaniforme, Jerarquía, Territorio, Estrategias políticas, Disgregación territorial.

\section{MARCO DE ESTUDIO}

Desafortunadamente, muchos trabajos de investigación arqueológica adoptan criterios de ordenación política actual para delimitar sus propios marcos de estudios, considerándose finalmente regiones -comunidades autónomas por ejemplo- que no tienen porqué corresponderse con espacios definidos en épocas pre-

1. Dpto. de Prehistoria y Arqueología de la Universidad de Sevilla. C/ María de Padilla, s/n, 41004. Becario de investigación de la Consejería de Innovación, Ciencia y Empresa de la Junta de Andalucía. E-mail: garciarivero@us.es

\begin{abstract}
This paper studies the Beaker phenomenon in the Middle Basin of the Guadiana River (Southern Spain) principally on the basis of the distribution of the pottery and the analysis of the archaeological contexts at macro-territorial and semi-micro scales. We present a synthesis of the development and problems surrounding research into this phenomenon at a European scale. In contrast with the generally widespread and recognised funerary association of the Beaker phenomenon, in our study area it appears to be related with uses and processes of a different nature. On the basis of the evidence currently available, we defend the idea of the restrictive prestige value of this pottery type and we suggest the close relationship of beakers with strategies of political clients promoted by part of the dominant sector of these human groups and communities.
\end{abstract}

Key words: Beaker, Hierarchy, Territory, Political strategies, Territorial disintegration.

históricas. Esto ha sido una tendencia general también en los estudios de Arqueología prehistórica sobre el Guadiana Medio y Bajo, y tenemos actualmente o bien trabajos concretos sobre territorio portugués o, en cambio, sobre territorio español.

En este caso, el área de estudio se ha delimitado con base en criterios geográficos, y ocupa la cuenca media del Guadiana (en adelante, CMG), con suelos de ambos países ibéricos. Posiblemente, problemas metodológicos de este tipo vayan solventándose en adelante, pues afortunadamente algunas instituciones autonómicas públicas están empezando a fomentar proyectos de índole política plural. 
En la margen derecha del río, el marco de estudio queda fijado por la cadena montañosa de Cáceres -Sierra de Montánchez, Sierra de San Pedro, las sierras de Alcántara-, la Serra de $S^{a}$ Mamede, el curso alto del río Degebe y el propio río Sado. La margen izquierda de la cuenca se ha fijado en Sierra Morena, concluyendo al suroeste en la Sierra de Aracena.

El Guadiana es un río de llanura y de curso lento, apenas tiene desniveles. Sobre el suelo paleozoico predominan las superficies de erosión, las rañas y los relieves residuales. El suelo terciario es igualmente llano. En general, la cuenca presenta una distribución hipsométrica muy favorable en la mayor parte de la región extremeña (Juárez 1979: 24).

Presenta una cierta diversidad de tierras mediterráneas, en variedades pardas ácidas y rojas no calizas, que con los aluviales y arenosos conforman la cuenca. Las tierras pardas meridionales se forman sobre rocas de granito, pizarra, cuarcita y arenisca. Los suelos rojos mediterráneos se desarrollan sobre materiales diversos, tales como la caliza y arcillas (Juárez 1979: 32-33).

Estas circunstancias hacen de la CMG un espacio muy favorable para la explotación agrícola y para la ocupación humana en el III Milenio a.C., y además constituye una importante vía de paso y plataforma de contacto entre las regiones colindantes (cuencas del Tajo y del Guadalquivir, y Meseta ibérica).

\section{HISTORIA DE LAS INVESTIGACIONES REGIONALES Y ESTADO ACTUAL DE LA CUESTIÓN}

Los estudios de arqueología prehistórica de la $\mathrm{CMG}$ son escasos. La situación es peor si nos referimos a momentos cronológicos o fenómenos concretos, como es el caso del Campaniforme. Esta situación se debe en parte a la gran atención suscitada desde hace décadas por los restos arqueológicos de otros períodos que, como en el caso protohistórico o romano, son innegablemente espectaculares. Esto ha influido, pues, de manera que la investigación prehistórica no cuenta con una amplia tradición.

En el caso concreto del Campaniforme, además, existen otros factores a tener en cuenta. En primer lugar, los primeros materiales campaniformes se encuentran con cierto retraso respecto a los hallazgos de otras regiones limítrofes. En 1886, E. Cartailhac publica, con especial atención en las decoraciones, algunos recipientes de tipo Palmela procedentes del estuario del Tajo (Cartailhac 1886: 123-126), y pocos años después, en 1894, se produce el hallazgo de la necrópolis meseteña de Ciempozuelos. A principios del siglo pasado, A. del Castillo elabora algunos trabajos sobre el conjunto de materiales de la región, que se subdivide en dos en relación a ambas submesetas (Castillo 1922: 1113 y 18; 1928: 49-53 y 196). Similarmente, en la comunidad andaluza los primeros hallazgos campaniformes se remontan al año 1899, cuando G. Bonsor excava la necrópolis de El Acebuchal (Bonsor 1899).

En cambio, en la CMG no se conocen materiales campaniformes hasta el año 1955, cuando se publican dos recipientes procedentes del Dolmen I de Casas do Canal (Leisner y Leisner 1955: Taf. 33, 15-16). Pocos años después, en 1961, se da a conocer un ejemplar acampanado sin decoración alguna procedente de Monte das Pereiras (Simôes y Freire 1961). En 1965 se publican los materiales campaniformes procedentes de Monte de Outeiro, concretamente dos recipientes lisos y una punta de tipo Palmela (Schubart 1965: Est. II, V y VI; 1965b: Abb. 5, a, b y d). Por último, en 1971 se conocen los hallazgos procedentes de São Bernardo (Veiga Ferreira 1971) y Aljustrel (Schubart 1971, Fig. 3, a).

En segundo lugar, los hallazgos campaniformes de esta región, además de aparecer posteriormente, son muy escasos respecto a los documentados en las zonas en derredor. Cuando R.J. Harrison publica su obra monográfica y otros artículos sobre el campaniforme ibérico (Harrison 1977, 1977b), los únicos emplazamientos y piezas conocidas son esas expuestas en el párrafo anterior.

Todos estos factores conformaron una imagen errónea sobre el Calcolítico Final de la CMG, que se consideraba un área marginal en cuanto al fenómeno campaniforme hasta hace si acaso una veintena de años. Hasta entonces, este fenómeno pasa inadvertido para los especialistas. Anteriormente, las referencias a la CMG habían sido vagas y escasas, anotaciones generales a partir de comparaciones sesgadas con las regiones circundantes. H. Schubart advirtió algunas diferencias, especialmente en los tipos de enterramientos y en la presencia/ ausencia de diversos ítems, entre las regiones del Bajo Tajo y Guadalquivir con las del Alentejo y Algarve. Según este autor, las dos últimas conformarían el "horizonte de Ferradeira" donde el supuesto pueblo "alóctono" responsable del desarrollo metalúrgico no habría influido como en las otras dos regiones (Schubart 1971). En un ensayo de sistematización de las cerámicas campaniformes del estuario del Tajo que se publica varios años después, se hacía referencia al sitio alentejano de Barrada do Grilo, y nos interesa saber que entonces se defendió que la cultura campaniforme se desarrollaba paralelamente a la fase tardía de la cultura dolménica del Alentejo y de la Beira, y que ésta última constituyó un obstáculo en la expansión del campaniforme hacia el 
interior peninsular (Leitão y otros 1978: 450 y 493), tomándose pues como causa del supuesto vacío que mostraba entonces el Medio Guadiana.

Como se adelantaba anteriormente, es realmente a partir de los años 80 cuando se empieza a considerar el territorio del Guadiana Medio con cierta propiedad, fundamentalmente debido al hallazgo de uno de los emplazamientos calcolíticos mayores de la península, La Pijotilla, en Badajoz. El hallazgo de numerosos restos del repertorio campaniforme, así como de otros elementos materiales coetáneos, sirvió para adelantar los primeros trabajos sobre el fenómeno campaniforme en esta área geográfica, y asimismo poner de manifiesto algunas de las relaciones de este territorio con otros bien distantes. Por ejemplo, uno de los estudios tomaba como base los campaniformes cordados y las decoraciones de pastillas repujadas, y subrayaba la influencia europea y la existencia de contactos con determinadas áreas culturales como el Sudeste francés (Hurtado y Amores 1982).

En la década de los 90, a medida que se van conociendo nuevos datos, se producen también consideraciones novedosas. Se va asentando una secuencia temporal tipológica que, con base en algunos fósiles directores como cazuelas carenadas, platos de bordes almendrados, etc., parece reflejar diferentes etapas calcolíticas. Además, se incorporan enfoques más amplios, de tal forma que por un lado cada emplazamiento se entiende en relación a su contexto natural y cultural, y por otro lado se van produciendo comparaciones entre ellos y también entre distintas regiones. En este sentido, cabe mencionar uno de los trabajos de R. Parreira donde se advierte de las diferencias en los tipos de asentamientos, unos fortificados relacionados con comunidades mineras y otros abiertos en suelos fértiles y llanos para la explotación agrícola (Parreira 1990: 33-34). La proliferación de poblados en el III Milenio a.C. junto con el acceso y explotación de recursos metalúrgicos y el sistema de control de intercambios lleva a un aumento de las necesidades de defensa y de la creación de identidades frente a otras comunidades, y se asiste a un establecimiento de territorios restringidos, lo cuál le lleva a advertir entonces una clara diferenciación entre los territorios de la Estremadura, el Alto Alentejo, el Alentejo litoral-valle del Sado, el Bajo Alentejo, el Alto Algarve y, por último, el Algarve litoral (Parreira 1990: 36).

Por esa fecha, ven la luz dos trabajos (Enríquez 1990; vide Extremadura Arqueológica II y IV, 1991 y 1995) que, si bien no tratan el fenómeno campaniforme en si, permiten dar a conocer un gran número de yacimientos arqueológicos y otros datos novedosos sobre el III Milenio a.C. en la CMG.
La segunda mitad de la década de los 90 ve aparecer los trabajos más explícitos sobre el Calcolítico y la transición al Bronce en la CMG. Además, tienen un carácter interpretativo más allá de los esquemas anteriores y proponen una secuencia de varias fases cronológicas-culturales y, asimismo, la existencia de un territorio política y/o económica y/o culturalmente articulado con La Pijotilla como centro aglutinador (Hurtado 1995; 1999; 2000).

Sin embargo, en los últimos seis o siete años, y debido a la construcción de la presa de Alqueva, se han encontrado varios asentamientos de esta época que han servido para retomar y plantear nuevas valoraciones sobre el fenómeno campaniforme y la ocupación de la CMG en el III Milenio a.C.

El hallazgo del asentamiento de San Blas (Cheles, Badajoz) en el flanco occidental del territorio de Tierra de Barros se interpreta, junto a otros del borde meridional como Huerta de Dios, como lugares de segundo orden instalados en la periferia para el control de recursos metalúrgicos en zonas ricas en minerales de cobre (Hurtado 2005: 327).

Por último, hay que mencionar un trabajo de A.C. Valera (2006) que se basa fundamentalmente en los poblados de la margen derecha del Guadiana en la región de Mourão. Este autor percibe unos «territorios de extensión media» estructurados mediante redes de poblamiento agregado, similares a los que plantea V. Hurtado, pero de tamaños menores y más dinámicos, en el sentido de que una comunidad se conforma por diversos asentamientos que se van construyendo, abandonando y reocupando, de ahí que insista en el análisis detallado de la estratigrafía y en cuestiones como el abandono de los sitios y la simultaneidad entre ellos. Igualmente, esta percepción de poblamiento activo la visualiza en el registro arqueológico, y propone que los asentamientos de menor tamaño de la zona donde aparecen cerámicas campaniformes son reocupaciones de sitios anteriormente abandonados (Valera 2006: 197).

Como ejemplo ilustrativo de estos territorios expone el caso de la Ribeira do Álamo con el asentamiento de Perdigões como centro catalizador. Considera dos niveles de relaciones o intercambios, que son altos a escala local-regional y relativamente bajos a escala transregional. Asimismo, anota que de forma similar parece producirse la distribución estilística de las cerámicas campaniformes, si bien la variabilidad existente en ciertos poblados indica que éstos actuaron como «centros organizadores» de determinadas áreas geográficas y como filtros en cuanto a la distribución de patrones decorativos y transferencia de productos exógenos a nivel transregional (Valera 2006: 174-176). 


\section{PROBLEMÁTICA CAMPANIFORME}

El estudio del fenómeno campaniforme ha ocupado un gran número de trabajos científicos desde hace aproximadamente un siglo. La amplia distribución geográfica de estos materiales arqueológicos, documentados en casi toda el área de la Europa actual y además, puntualmente, en otras zonas geográficas como es el caso del norte del continente africano, supone una de las causas principales de la atención que desde entonces se ha dedicado al análisis de este fenómeno. Además, ciertos aspectos tecnológicos de gran depuración en la elaboración de estos objetos como el buen acabado y la calidad de la cerámica, y la profusa decoración que ésta exhibe, han supuesto también factores importantes en cuanto a la valoración de estos recipientes $\mathrm{y}$, por tanto, en la gran cantidad de estudios llevados a cabo sobre el fenómeno cultural que los envuelve.

A lo largo de todo este proceso de estudio, la visión general sobre este fenómeno ha ido cambiando, en parte como consecuencia del contexto político, social y académico desde donde se han ido desarrollando estas interpretaciones (Garrido 2001; 2005: 30). De este modo, se comprende que durante la primera mitad del siglo XX, época de las Guerras Mundiales y donde predomina sobre cualquier otro el difusionismo como marco de explicación, el fenómeno campaniforme se entendiese a modo de un pueblo guerrero y conquistador de nuevos territorios y riquezas, que llegaría a expandirse físicamente a escala paneuropea. Sin embargo, a partir de los años 70 de ese mismo siglo, en los inicios de la construcción de un amplio marco político común como el europeo con una tendencia hacia la internacionalización de mercados, y cuando empieza a desarrollarse académicamente la corriente autóctona que aún actualmente prevalece de manera mayoritaria, la visión general del fenómeno campaniforme cambia bruscamente. $Y$ es que desde entonces, se cree fruto de las relaciones políticas y económicas entre los asentamientos y comunidades, sin apenas necesidad de movimientos de gentes, sino mediante unas redes fundamentalmente económicas que difunden estos materiales a modo de bienes de prestigio o de servicio a lo largo de un vasto espacio geográfico (Clarke 1976).

Los aspectos más discutidos del fenómeno campaniforme son principalmente dos: por un lado su origen y las vías de promoción, y por otro su significado o más bien las razones de su extensa difusión.

Respecto al primero de los aspectos, las primeras explicaciones se enmarcan dentro del paradigma ex oriente lux y se deben a autores como Montelius, Petrie o Déchelette que vincularon estas cerámicas con las civilizaciones del Próximo Oriente (Garrido 2005: 30).
A partir de los años 20 del siglo XX, predomina un enfoque que traslada a Occidente el territorio principal y de origen de este fenómeno (Schmidt 1915; BoschGimpera 1940; Siret 1913: 208, Fig. 80; Castillo 1922; 1928; 1943; 1944). No obstante, G. Childe apoyaba el esquema anterior, y entendía la difusión de esas cerámicas procedentes del Próximo Oriente a manos de un pueblo colonizador que asimismo era responsable de la expansión de la metalurgia por Europa (1958: 146-147). Eso sí, situaba el origen de ese pueblo en Centroeuropa (1947: 223; 1958: 145).

El origen exclusivamente portugués del campaniforme se refrenda mediante algunos trabajos en los años 60. B.M. Blance había argumentado un desarrollo desde el grupo cerámico local conocido como "copos", de VNSP I (1960; citado en Harrison 1977: 5).

Pero una vez se forja la idea de que existen diversos caracteres campaniformes propios de diferentes núcleos geográficos, y que por tanto no todo parece originarse en la Península Ibérica, E. Sangmeister da a conocer la "teoría del reflujo" $(1963 ; 1966)$.

Existía desde años atrás una hipótesis que proponía un origen múltiple del campaniforme, de forma análoga, en dos zonas: por un lado en Iberia, y por otro en Bohemia (Palliardi 1919, citado en Harrison 1977: 5): la conocida como "modelo dual". Pero la propuesta más extrema en lo que a orígenes múltiples del campaniforme se trata, llega a establecer un número de seis redes diferentes destacando los territorios del Rin, de Europa Central, de los Países Bajos, de Iberia y del área ródano-renana (Gallay 1988; 1998).

Avanzados los años 70, R.J. Harrison (1977) elabora la obra más completa sobre el campaniforme de la Península Ibérica. Este estudio defendía un origen del campaniforme Marítimo en el centro de Portugal, que se desarrolla a partir de la cultura local VNSP II (Harrison 1977: 29), pero apoya igualmente la distribución de estas cerámicas desde el Tajo al ámbito bretón, donde se fusionan con el AOC desembocando en los híbridos conocidos como CZM. En definitiva, apoya la factibilidad de un origen dual del campaniforme, siguiendo la línea de los estudios previos aunque modificando algunos aspectos respecto a las hipótesis anteriormente planteadas.

Actualmente, una gran parte de los investigadores apoya que el foco difusor de las primeras cerámicas campaniformes es el valle del Bajo Rin. Esta vertiente que se conoce como el "modelo holandés" fue definitivamente propuesta en el congreso de Oberried por J.N. Lanting y J.D. Van der Waals (1976). Básicamente, proponen una secuencia PFB (Protruding Foot Beaker Culture)AOO (All Over Ornamented)-BB (Bell Beaker), que se corresponde localmente con los periodos Uppergrave y 
Groundgrave (Lanting y Waals 1976: 13), y subdividen el BB en dos grupos: Marítimo y, posteriormente, estilos regionales (Lanting y Waals 1976: 36-37).

El origen nórdico de las cerámicas campaniformes debe concebir entonces una difusión en sentido meridional, llegando a la fachada atlántica europea (Gran Bretaña e Irlanda, Francia e Iberia), Centroeuropa y la parte oriental europea. En este sentido, cabe mencionar un estudio sobre las vías de intercambio entre los grupos campaniformes a lo largo del territorio francés (Treinen 1970, citado en Alday 2001: 148).

Las vías de promoción de las cerámicas marítimas y mixtas puntilladas-cordadas, fundamentalmente aquellas que conciernen al interior de la Península Ibérica, han sido tratadas recientemente (Alday 2001). Este trabajo resta valor a la distribución "vía marítima", consolidada entre otras cosas por la ausencia de estos elementos en el interior de las fachada atlántica francesa-española hasta hace poco tiempo, y defiende la importancia de los contactos "vía terrestre", que mediante los principales ríos ponen claramente en relación, al menos, el centro de Portugal y la península bretona, y que asimismo explicaría la presencia de ciertos elementos orientales en la Península Ibérica llegados a través de Aquitania (Alday 2001: 112-116).

No obstante, el modelo holandés y, consecuentemente, el sentido Norte-Sur de la difusión del campaniforme no están exentos de objeciones. Los detractores de esta corriente siguen defendiendo actualmente el origen del campaniforme en la Península Ibérica, concretamente en el estuario del Tajo. Señalan la proporción cuantitativa mayor de las cerámicas marítimas en el centro de Portugal respecto al resto de regiones geográficas, y concretamente respecto al valle del Rin (Case 2004: 12; Salanova 2004: 69; 2005: 13-14). Igualmente, destacan la gran variabilidad técnica y estilística que presenta dicha región portuguesa (Salanova 2000; 2004: 69). Otro argumento sobre el que se siguen apoyando los trabajos recientes es la continuidad que muestran los sitios arqueológicos del lugar a lo largo del III Milenio a.C. (Salanova 2005: 8). También se ha subrayado la similitud morfológica, sugerida anteriormente (Blance 1971:115, citado en Kunst 2005: 205), entre los recipientes del substrato local calcolítico con aquellos otros de tipo campaniforme, así como la semejanza de ciertos motivos decorativos y la continuidad de otros, como es el caso de la "hoja de acacia", a lo largo de ambas fases cronológicas (Kunst 2001: 82-84; 2005: 205). Pero el argumento de mayor importancia reside en una, presumiblemente, mayor antigüedad de los tipos marítimos Atlánticos y del Suroeste europeo (Strahm 1979; Müller y Willigen 2001; Case 2004: 12;
Salanova 2005: 12-13; Kunst 2005: 208), pues el grupo nórdico no parece sobrepasar la fecha de 2500 a.C.

Recientemente, en un intento de convergencia de ambas perspectivas básicas, se retoma la idea de los orígenes múltiples; en este caso se propone un origen del AOO en Holanda y de las marítimas en la Península Ibérica (Kunst: 2005: 202), ya que con base en las fechas radiocarbónicas de Holanda y del Suroeste de Europa no parece posible sostener que las cerámicas marítimas procedan de aquellas otras cordadas (Strahm 1979: 289-291).

El segundo de los aspectos fundamentales del fenómeno campaniforme, el significado o las razones de su difusión, también ha ido evolucionando a la par del contexto de los investigadores. En un principio, los objetos campaniformes caracterizaron de forma exclusiva la cultura material de ese pueblo colonizador. Junto a las cerámicas decoradas, los utensilios de metales, tales como puñales de lengüeta, puntas Palmela y otros objetos de uso decorativo como los botones de hueso y ciertos objetos de oro complementaban el repertorio material. Posteriormente, una vez el registro material de los yacimientos arqueológicos empezaba a estudiarse de forma más completa y sistemática, queda en entredicho esta idea, ya que la cantidad de estos objetos campaniformes normalmente supone sólo una pequeña parte del total del material documentado.

Existe una cierta variabilidad de hipótesis planteadas sobre el uso y la funcionalidad de estos recipientes. Hay quienes no conceden un carácter excepcional a estas piezas cerámicas, y las interpretan como un tipo cerámico de uso relativamente común en diversos contextos sociales (Salanova 1998; 2001: 98; 2005: 9; Brodie 1998), si bien se le reconoce su vinculación a rituales de enterramiento (Case 1995; Case 2004: 29). Esta perspectiva minimiza el valor de prestigio de estas piezas (Brodie 1998; Salanova 1998) básicamente porque provienen de contextos locales (Convertini 1996; Convertini y Querré 1998; Clop y Molist 1998; citados en Salanova 2005: 9).

No obstante, la mayoría de interpretaciones sobre estas cerámicas apuestan por su carácter exclusivo y peculiar. A este respecto, hay que citar el estudio realizado por Clarke (1976) que, mediante comparaciones con el registro etnográfico, muestra la necesidad de una porción mayor de tiempo y trabajo para la elaboración de esos recipientes (Clarke 1976: 469). Este incremento de inversión aumenta el coste y el valor de estos objetos, convirtiéndolos en elementos de prestigio que despliegan el estatus social de aquellos que las poseen, y que fueron usadas incluso para el intercambio a grandes distancias entre varias comunidades, donde su papel utilitario y su valor 
funcional fueron secundarios (Clarke 1976: 462). Según otros autores, estas cerámicas conformarían una especie de "paquete de culto" que se utilizarían en ceremonias sociales y/o rituales de aceptación internacional (Burgess y Shennan 1976). Por otro lado, otras explicaciones matizan este esquema básico e interpretan el campaniforme bajo una funcionalidad más definida y concreta. Por ejemplo, que tales objetos forman parte de unas pautas culturales, de unas estrategias de comportamiento destinadas a fines concretos. A este respecto, hay que apuntar los trabajos de A. Sherrat $(1987 ; 1991)$, que imprimen un enfoque novedoso y original al fenómeno campaniforme. La transferencia de materiales mediante un mercado de larga distancia se basa en la apropiación de estos elementos por parte de un sector de la sociedad, en un proceso de ostentación personal (despliegues individuales frente al dominio colectivo anterior). En la difusión de estos elementos desde unas zonas a otras hay que tener presente un factor clave: el consumo ritual de sustancias psico-activas. En el momento de la eclosión campaniforme, desde el valle del Rin, la sustancia empleada es básicamente algún tipo de bebida alcohólica que funciona a modo de «lubricante social» o «agente de hospitalidad» (Sherratt 1987: 82 y 91), aunque no parece descartarse el uso de otras sustancias (Sherratt 1991: 57). Desde esta postura, y en definitiva, hay que anotar que los recipientes campaniformes se utilizarían en unos ritos sociales relacionados con el empleo y consumo de sustancias alcohólicas y que servían como medios de legitimación del poder para unas clases sociales emergentes (Sherratt 1987; 1991; Garrido 1995; 1997: 204; Garrido y Muñoz 2000), y que posiblemente podrían también destinarse en último término a la captación de seguidores o, incluso, de sectores o individuos humanos al servicio guerrero (Sherratt 1987: 90 y ss.; Garrido 2005: 36).

La vinculación del campaniforme con ambientes funerarios ha sido destacada, en cambio, por la mayoría de autores, incluso en estudios referentes a áreas geográficas muy diversas. Pero la concepción que se tiene de estos elementos dentro de los rituales de enterramiento varía considerablemente para unos y otros autores. R. Boast (1995) realiza un estudio del campaniforme inglés concluyendo que estos objetos son especiales porque están asociados con lo mundano, pero que no tienen un valor especial o de prestigio inherente, y que fueron usados en actividades cotidianas. En definitiva, cree que las actividades cotidianas de producción y consumo de comida y festejos comunales se transfieren a los enterramientos mediante el repertorio campaniforme, transformando lo mundano en etéreo. Asimismo, el campaniforme podría contener mensajes de género, estatus, obligaciones filiales, etc. (Boast 1995: 78).
Por otro lado J. Thomas argumenta que, aunque se produce un aumento de la variabilidad cultural y de la complejidad, el uso del campaniforme en las prácticas funerarias no parece suponer una brusca ruptura con el pasado, sino que más bien afirma la continuidad de las tradiciones locales de cada región, aunque eso sí, de forma selectiva, estructura y estandariza estas costumbres anteriores (Thomas 2005: 111-112). Señala una evolución gradual hacia la individualidad en los enterramientos y concluye que en territorio británico el significado prioritario del repertorio campaniforme estriba en el asentamiento y en la continuidad genealógica de grupos, seguramente un sector de población que intenta afianzar un tipo particular de identidad relacionada con los ancestros, si bien es cierto que otros casos del registro parecen evidenciar otros aspectos de género, edad, etc. (Thomas 2005: 115-116).

H. Case piensa que el uso del campaniforme no se reduce a determinados roles especiales, sino que también sirve como cerámica de uso cotidiano (Case 1995), sin embargo reconoce su significación simbólica dentro del complejo de asociaciones funerarias (Case 2004: 29). A este respecto, y dentro de una esfera mítica, interpreta estos materiales como un equipamiento simbólico de caza mayor, «de los monstruos del mundo espiritual», y que mediante unos despliegues competitivos acentúan las tradiciones pasadas y la fuerza de los ancestros para proteger a los vivos. Asimismo, anota que según el registro estos atributos se reservan a unos determinados grupos privilegiados (Case 2004: 29).

Otro enfoque, bien distinto y de gran originalidad, es el propuesto por N. Brodie quién concibe las cerámicas de tipo campaniforme como una tecnología importante de expresión personal para la construcción y el mantenimiento de la identidad del género femenino. Anota que los ajuares funerarios indican una doble categoría referente a la polaridad entre géneros. Esta dicotomía simbólica entre géneros, y las competencias productivas culturales de cada sexo son visibles en numerosos casos etnográficos, como en el Pacífico Norte (Brodie 1997: 301; 2001: 489). Posiblemente en los enterramientos, las obligaciones de las mujeres serían posiblemente suministrar al difunto alguna comida y bebida - con sus contenedores campaniformes-, mientras que los hombres podrían contribuir con armas, herramientas u otros ornamentos (Brodie 2001: 491). Las cerámicas campaniformes se producirían así en contextos domésticos a mano de las mujeres, y la variabilidad en la calidad y en la decoración de aquellas puede relacionarse con diferencias intra-sociales, que aumentan la complejidad de la cultura campaniforme (Brodie 1997: 302; 2001: 488). La difusión geográfica de estos 
elementos o ideas requiere de un aprendizaje de la técnica y de otros menesteres que necesitaban de un contacto físicamente próximo entre individuos. Por tanto, destaca el movimiento de mujeres entre distintos grupos culturales. Fundamentalmente, estas conexiones se realizarían mediante sistemas de parejas o matrimonios y por abducciones, y explican en parte la difusión de estas cerámicas desde el valle del Rin hacia el Este y el Sur, y asimismo la expansión de la metalurgia del cobre desde el Sureste hacia el Noroeste, a través de lo que se ha denominado la frontera calcolítica (Brodie 1997: 306-310; 2001: 493-495).

La aceptación de unas u otras explicaciones es una tarea francamente difícil, básicamente porque sus aprobaciones $-\mathrm{y}$ fundamentalmente sus refutaciones- deben de basarse en un registro arqueológico que no parece fácilmente palpable al menos en cuanto a estos aspectos se refiere.

De este modo, gran parte de las hipótesis anteriormente planteadas sobre el significado y el uso del campaniforme son potencialmente explicaciones válidas, sobre todo teniendo en cuenta el área geográfica tan inmensa por el que se extienden. Incluso en algunas ocasiones algunas de estas perspectivas no tienen porqué ser excluyentes.

Es por ello, que resulte complicada una explicación única para todo este fenómeno, y que desde hace algunos años se venga advirtiendo de la necesidad de estudios a escalas regional y local, donde se tengan en consideración los contextos económicos y sociales propios de cada región y de cada sitio (Chapman 1987: 64).

\section{ANÁLISIS DE LAS EVIDENCIAS DEL REGISTRO ARQUEOLÓGICO}

Un total de 53 yacimientos con cerámicas de tipo campaniforme se conoce actualmente en la CMG. La mayoría de los sitios son asentamientos; concretamente, 41 de ellos. Son los que siguen a continuación: Monte do Tosco I, Cerros Verdes 4, Outeiro de São Bernardo, Castelo Velho de Safara, Peña de San Sixto, Sala $n^{\circ} 1$, Três Moinhos, São Brás 1, Chapéu de Ferro de Algares, Molino Perdido, Morro de Nostra Senhora, Morro da Mangancha, Porto Torrão, Monte da Tumba, Monte da Ponte, Monte do Pombal, Fonte Ferrenha, Terrugem, Famão, Castelo de Noudar, La Palacina, Cerro Cabril, El Pedrosillo, Los Palacios, Palacio Quemado, San Pedro, S. Gens, Barrada do Grilo, Aljustrel, La Sarteneja, Peñas Blancas, Apeadero de Zarza de Alange, Vista Alegre, Los Corvos, Trasera de la Pepina, Porto das Carretas y Miguens 3.
En 4 casos, además, se ha documentado un área de necrópolis dentro o cerca del territorio de hábitat. Son los ejemplos de San Blas, La Pijotilla, Perdigões y Escoural.

Por otro lado, existen 10 casos de sitios exclusivamente funerarios: Monte das Pereiras, Monte do Outeiro, Casas do Canal I, Estremoz 10, Dolmen de Lácara, Anta de Bencafede, Barbaño, Zayas, Guadajira y Dolmen 1 da Herdade de Carneiro.

Hay un caso indeterminado, denominado Huerta de Dios, aunque se ha documentado una estructura posiblemente funeraria. Las características de esta estructura circular y los elementos que aparecen en ella -ídolos de diversos tipos, bastones betiloides, punzones, un peine y espátulas en hueso, otra espátula de marfil y varios elementos líticos significativos- hicieron pensar que pudiera tratarse de un monumento funerario (Enríquez 1989: 155), posiblemente tipo tholos, pero parece que esta estructura se inserta dentro de un poblado que se estima con un tamaño de 10 ha (Hurtado 2005: 325). Y por último otro sitio peculiar que se trata de la ocupación de un covacho natural, denominado Covacho del Monje.

Se han estudiado más de 300 registros cerámicos de tipo campaniforme de la CMG. Además, nueve casos se refieren a grupos de materiales indefinidos cuantitativamente. Se trata de varios sitios con conjuntos que no están detallados en sus publicaciones respectivas. En estos casos, hemos asignado una única sigla a cada grupo, a sabiendas de que posiblemente se conforme por un número superior de registros. Aparte de estos casos, existe un décimo, Porto Torrão, donde se ha registrado individualmente un gran número de fragmentos campaniformes, mientras que otros tantos no suficientemente descritos en las publicaciones se enumeran bajo una misma sigla. En definitiva, el total del conjunto cerámico campaniforme actualmente conocido en la CMG parece sobrepasar los 400 ejemplares.

El conjunto cerámico muestra un grado de fragmentación bastante avanzado. La gran mayoría de registros se corresponden con sólo un fragmento cerámico del recipiente. Estos casos ocupan el 84,7\% del total del conjunto. Dado el alto grado de fragmentación del registro y la relativa homogeneidad de formas del campaniforme, no se ha procedido a la realización de un estudio tipológico a gran detalle. Se ha limitado este aspecto a las categorías principales básicas: vaso, cazuela y cuenco. Sólo un 33,2\% de los casos puede identificarse con alguna forma cerámica concreta. Los cuencos y los vasos, en este orden, son los tipos de recipientes más comunes. En menor medida se documentan las cazuelas, y los tipos más peculiares como los especimenes globulares y el cuenco Palmela son claramente minoritarios. Los tipos principales son vasos, cazuelas y cuencos y 
se distribuyen de formas similares, si bien la cantidad de los cuencos parece ser superior en el área alentejana.

Estas tres formas son arquetípicas y aunque tienen cierta variabilidad entre los ejemplares de cada grupo se reconocen fácilmente $\mathrm{y}$, lo más interesante, tienen patrones morfológicos relativamente bien definidos. El ejemplo exponente que, sin dudas, mejor ilustra este asunto es el clásico Vaso campaniforme. El análisis morfométrico de los recipientes de este tipo en nuestro conjunto demuestra un proceso y un modelo de manufactura muy estandarizado, hasta el punto de que existen correlaciones muy significativas entre muchas de las variables estudiadas. Asimismo, es el vaso el tipo de recipiente que se distribuye de una forma más regular. Igualmente, es muy revelador que se trate también del único tipo de recipiente que se encuentra en todos los tipos de estructuras funerarias y en todos los contextos de enterramientos del Medio y Bajo Guadiana, con excepción de sólo dos casos. Refleja un elemento común, un símbolo estándar que según algunos autores no sólo sería aceptado a nivel local o regional, sino a escala internacional (Burgess y Shennan 1976; Salanova 2004; 2005).

Por otro lado, existe además al menos una media centena de registros que poseen motivos similares al campaniforme, aunque no pueden ser adscritos a este tipo cerámico. Se trata de decoraciones fundamentalmente mediante la técnica incisa, aunque también se encuentra el puntillado y la impresión. Muchos de esos casos pueden englobarse dentro del grupo de la cerámica con decoración simbólica.

\subsection{Los asentamientos}

\subsubsection{Escala Macro-territorial}

Se puede distinguir tres áreas básicas en la localización de estos sitios respecto al curso del río: la ubicación en tierras llanas a lo largo de la propia vega del río Guadiana; por otro lado, aquella otra en territorio periférico al valle de este río. Se trata de emplazamientos que, aunque dentro de la cuenca general del río, se ubican tierra adentro y a alturas algo mayores. En tercer y último lugar, aquellos situados en zonas interiores, de sierra suave.

Los sitios que pertenecen a la primera de estas ubicaciones se sitúan en torno a los 150-200 m. Los que se ubican en el área periférica próxima al mismo valle muestran alturas algo superiores (200-400 m). En último lugar, aquellos tierra adentro alcanzan alturas normalmente superiores a los $400 \mathrm{~m}$. Ejemplos de este tipo se encuentran en el Alto Alentejo, como Fonte Ferrenha, o en la comarca de la Serena y en la campiña de Llerena, como El Pedrosillo y Los Palacios.

Los enclaves próximos al Guadiana se ubican generalmente sobre la topografía de aluviones y terrazas del mismo valle. Los más alejados lo hacen sobre un territorio meseteño generalmente llano con suaves elevaciones. En términos generales, merece destacar la ubicación de los yacimientos sobre cerros y lomas, aspecto bastante frecuente a lo largo de todo el territorio.

Un aspecto común entre, prácticamente, la mayoría de los poblados es la ubicación próxima a recursos hidrográficos. El área próxima al propio curso del Guadiana es la zona que concentra mayor número de emplazamientos. El resto de yacimientos están emplazados cerca de afluentes del río anterior u otras vías fluviales secundarias, que se relacionan con estos cursos hidrográficos gregarios. Además, algunos de los sitios se encuentran junto a manantiales y acuíferos. Por tanto, la distribución del campaniforme se relaciona con el sistema de redes hidrográficas de estos territorios. A modo de ejemplo, valga señalar las distribuciones de yacimientos con campaniforme, que desde el Guadiana hacia tierra adentro, se ubican a lo largo de las riberas del Matachel, del Guadajira, del Ardila, del Chanza -en el lado español-y del Lucefece y del Degebe -en la parte portuguesa-. Un río de vertiente atlántica que parece haber jugado un papel importante en la distribución del campaniforme por el lado occidental del territorio es el Sado, e igualmente su afluente denominado Roxo.

Se ha puesto especial atención en el tamaño de los asentamientos. Aunque no ha sido posible concretar esta cifra para todos los sitios (debido a la falta de excavaciones arqueológicas) y no contemplamos pues sino una parte del panorama, los datos disponibles resultan ya interesantes. Se hace evidente una línea de asentamientos de mayores tamaños (Categoría u orden 1) que, en sentido Noreste-Suroeste, va desde la región emeritense hasta el tramo central del río Sado. Los poblados de mayores dimensiones son Porto Torrão, con 100 ha, y La Pijotilla, con 80 ha, ambos situados en los extremos de la línea anterior. Entre estos, justamente en la misma recta trazada, se ubican los poblados de San Blas -en la margen izquierda y ocupando aproximadamente unas 50 ha con el área de necrópolis incluida-y Perdigões -en la margen derecha y con 16 ha-

Además, habría que citar el asentamiento de Monte da Ponte, al Noroeste de Perdigões en el Alto Alentejo, que ocupa 7 ha. Quizás, su extensión y, sobre todo como veremos posteriormente, su innegable carácter defensivo responden a la propia ubicación estratégica del sitio entre las áreas culturales de la CMG y del estuario del Tajo. 
Lo destacable de los asentamientos que siguen en tamaño (Categoría u orden 2) es su propia ubicación, delimitando el área de la CMG. En torno a la región emeritense, donde el Matachel confluye con el Guadiana, se encuentran los poblados de La Palacina y Vista Alegre, con 1,2 y 1,5 ha, respectivamente. Hacia el Sur, en el río Ardila, se puede apuntar el caso de Trasera de la Pepina, de 1,5 ha. En la zona meridional de la CMG, prácticamente dando lugar al tramo bajo del río, se encuentra el poblado de Três Moinhos que ocupa una extensión de 2 ha. Otros asentamientos de menor dimensión posiblemente pudieron funcionar a modo de localizaciones satélites de los poblados mayores. Cabe citar el caso de Porto das Carretas, de una 1 ha y situado bastante cerca de San Blas. El resto de asentamientos documentados (Categoría u orden 3) o tiene una extensión menor a media hectárea o no se dispone aún de información suficiente.

Otro aspecto de los poblados que merece ser tratado de forma particular es la presencia de recintos de delimitación, ya sea mediante fosos o murallas. Igual que en lo relativo-al tamaño, tampoco aquí se cuenta con la información total de todos los poblados. Muchos de ellos han sido sólo prospectados en superficie, otros sólo excavados muy parcialmente. No obstante, con base en las intervenciones arqueológicas realizadas hasta el momento se pueden tratar distintos aspectos concernientes a los sistemas de recintos.

Existe una cierta variabilidad entre los asentamientos respecto a las características estructurales de estos recintos. Algunos disponen de diversos recintos concéntricos fortificados, mientras otros sólo contienen delimitaciones a base de fosos excavados en la tierra. La comparación de estos sistemas entre unos y otros poblados puede resultar arriesgada, en cuanto a que el estado o producto final muchas veces sólo refleja el último momento o fase de la actividad dinámica de estas construcciones. Muchos procesos de derrumbes y nuevas edificaciones dificultan francamente la comprensión detallada de estos procesos diacrónicos y transformacionales. No obstante, este obstáculo influye en una gran cantidad de aspectos del registro arqueológico general, y no deben de dejarse a un lado. Los casos donde no se hayan realizado intervenciones suficientes para alcanzar aproximaciones más detalladas no deberían subestimarse a la ligera. Al fin y al cabo, los sistemas de recintos de poblados conformados por un número mayor de estructuras están indicando una cierta importancia del sitio. No siempre estos casos pueden interpretarse como conjunto, en el sentido de que todas esas estructuras se construyesen o funcionasen en un mismo momento. Ahora bien, no hay dudas en cuanto a que de algún modo estos sitios muestran una clara continuidad en la inversión constructiva, que de alguna forma subraya ese carácter frente a otros asentamientos sin estructuras de ese tipo.

El primer asentamiento es Perdigões, que tiene seis fosos subcirculares concéntricos. No se sabe aún si funcionaron de manera simultánea o responden a distintas generaciones tras el derribo de algunas de ellas. Además, parece ser que pudieron haber funcionado como sistema de drenaje y captación de aguas. En el foso exterior han sido documentados estructuras derruidas pero no se conoce con seguridad si se trata de una muralla u otro tipo de estructura de acceso al interior del poblado. Se documenta una necrópolis en el interior del sexto recinto, en el lado Este, en la misma dirección que el recinto megalítico (cf. Lago y otros 1998; Valera y otros 2000).

En segundo lugar, el poblado de Monte da Ponte (cf. Kalb y Höck 1997; Boaventura 2000: 295), que cuenta con una torre central y al menos dos recintos concéntricos que no pertenecen al poblado posterior de época Moderna. Se documentan fases de reparaciones o refuerzos en la primera línea de muralla. También se registra un bastión. Más allá de la cuarta muralla (no se especifica la cronología) existen, según la prospecciones geofísicas y magnéticas, otros recintos hasta el momento no identificados. Podrían ser murallas, fosos o alguna empalizada.

Otros yacimientos destacados en cuanto a las características del sistema de recintos son Monte da Tumba, Porto das Carretas y Palacio Quemado, que disponen de tres líneas de murallas. El sistema defensivo de Monte da Tumba (cf. Tavares da Silva y Soares 1987; Soares y Tavares da Silva 1985) abarca un intervalo cronológico que va desde el Neolítico Final/Calcolítico I hasta época campaniforme (fase III), cuando en el centro del asentamiento se concluye construyendo un torreón subcircular de unos $12 \mathrm{~m}$ de diámetro de base. En Porto das Carretas (cf. Tavares da Silva y Soares 2002: 179) se conocen diversas líneas de murallas guarnecidas por torres y bastiones en la Fase I, precampaniforme, pero no se documentan estructuras en la Fase II, campaniforme. En Palacio Quemado (cf. Hurtado y Enríquez 1991) se conocen tres líneas de murallas, un bastión y una estructura que parece una plataforma. Corresponden a dos fases de ocupación; en la segunda se expande ligeramente el espacio delimitado.

En el poblado de San Blas (cf. Hurtado 2004) se conoce una muralla exterior de $1,8 \mathrm{~m}$ de anchura y casi $2 \mathrm{~km}$ de perímetro a la que se asocian un leve foso, un bastión y una puerta defendida unos torreones semicirculares; además, existe un recinto interior de forma elíptica y de unos $130 \mathrm{~m}$ de diámetro aproximadamente. 
Se trata de una muralla de igual anchura a la del recinto exterior y se le asocia un foso de sección en U de aproximadamente $4 \mathrm{~m}$ de profundidad respecto al nivel de suelo y $10 \mathrm{~m}$ de anchura.

El poblado de São Brás se fortifica mediante dos murallas concéntricas que coinciden con sendos declives de las terrazas de la loma; en la muralla interior se documenta un bastión semicircular (Parreira 1983).

Al parecer, el yacimiento de San Pedro también parece tener dos recintos fortificados, que corresponden a fases del Calcolítico Pleno y Final, pero según el arqueólogo ambas construidas con anterioridad a la presencia de campaniforme (Calado 2001: 255; Calado, información oral).

El yacimiento de La Pijotilla (cf. Hurtado 1984; 1986; 1991; 2000) dispone de dos fosos concéntricos de tendencia circular. El exterior tiene un diámetro de $1 \mathrm{~km}$ y un perímetro de $3 \mathrm{~km} \mathrm{Su}$ anchura varía de 4 a $10 \mathrm{~m}$. Se han documentado restos de murallas asociadas a este foso. El foso interior no se documenta completo, sólo un sector semicircular, y se extiende por el lado occidental del arroyo Pijotilla. Su anchura es de $14 \mathrm{~m}$. No se conoce la asociación de murallas a este último foso.

Son varios los poblados que disponen de un único recinto fortificado. Son los casos de Tres Moinhos (cf. Monge Soares 1992; Monge, Araújo y Peixoto 1994: 170), Escoural (cf. Soares y Tavares da Silva 1985; Valera, Valera y Farinha 1983), El Pedrosillo (cf. Enríquez 1989: 152-153; Enríquez 1990: 80-81; Enríquez e Iñesta 1985), Los Palacios (cf. Enríquez 1989: 15657; Enríquez 1990: 82-83; Enríquez e Iñesta 1985), S. Gens (cf. Calado 1993: 64; 2001: 256) y Trasera de la Pepina (cf. Enríquez 1989: 173 y ss.; Enríquez 1990: 89; Hurtado 1999: 51).

Finalmente, en Porto Torrão se conoce la existencia de dos fosos paralelos. El Foso 1 tiene unas dimensiones de 3,50 m de longitud en la boca; 2,50 $\mathrm{m}$ en la base; y una profundidad de $3 \mathrm{~m}$. Se fecha en el Neolítico Final. Aunque en ninguno de los fosos hay restos de empalizadas o estructuras positivas, en el lado interno del Foso 1, hay una zanja de $1 \mathrm{~m}$ de largo. Por otro lado, el Foso 2, de sección en $\mathrm{U}$ con fondo aplanado, con una longitud de 5,90 $\mathrm{m}$ y una profundidad de 3,40 $\mathrm{m}$. Se fecha en el Calcolítico Pleno, si bien en la parte superior de su colmatación tiene cerámica campaniforme (Valera y Filipe 2004).

A priori, parece que los yacimientos de cierto tamaño disponen asimismo de recintos delimitadores con fosos. Ahora bien, estas estructuras no se limitan en absoluto a los grandes poblados; además, en muchos asentamientos menores existe un carácter defensivo mucho mayor que en otros de mayor tamaño. Valgan la comparación entre Porto Torrão por un lado, y Monte

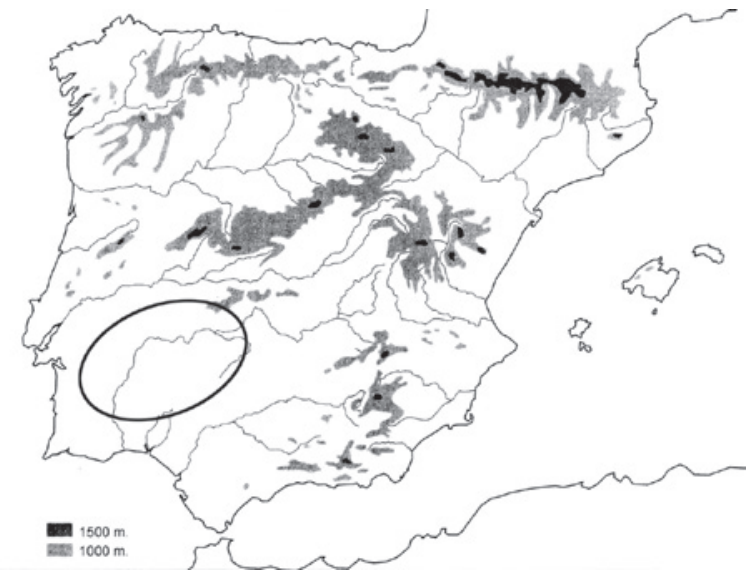

Figura 1: Marco de estudio. Situación de la Cuenca Media del Guadiana en la Península Ibérica.

da Tumba, Porto das Carretas y Palacio Quemado por otro. Además, ahora sólo estamos atendiendo a los poblados con material campaniforme. Un mapa publicado hace algunos años sobre la distribución de los asentamientos en la zona de Tierra de Barros (Hurtado 2000, Figura 1) muestra la gran cantidad de poblados fortificados de pequeño tamaño sin material campaniforme alguno. Podemos pensar, por tanto, que no existe una relación importante entre el tamaño del sitio y nivel de complejidad de los recintos.

Más sentido tiene relacionar el grado de complejidad o de desarrollo de los recintos de los poblados con otros elementos, presumiblemente, relacionados con la funcionalidad estratégica concreta de cada zona y del propio poblado en relación al resto de asentamientos de un mismo territorio, obedeciendo por tanto a patrones de escalas territoriales. A este respecto, es interesante destacar que los poblados con sistemas de fortificaciones más complejas (Perdigões, Monte da Ponte, Porto das Carretas, Monte da Tumba, San Blas y, en menor medida, San Pedro, Escoural y S. Gens) se encuentran fundamentalmente cerca del propio curso del río y, también, en el área geográfica a caballo entre el Guadiana Medio y el estuario del Tajo.

Por otro lado, resulta interesante recordar la multitud de poblados fortificados en el reborde oriental de Tierra de Barros, que parece indicar el límite oriental de un territorio bien definido (Hurtado 1995; 1999; 2000). En este mismo flanco, junto a Almendralejo, se excava actualmente un nuevo poblado fortificado con bastiones y con cerámica campaniforme ya conocido previamente en las prospecciones de V. Hurtado (2000) como Cortijo de Zacarías. 


\subsubsection{Escala Semi-micro}

En el asentamiento de San Blas (Cheles, Badajoz) se han contabilizado como campaniformes propiamente dichos un total de 19 registros, todos en ambientes relacionados con cabañas circulares. De ellos, 14 se localizan en el corte J27, al interior de la ciudadela. Sólo 5 registros se documentan al exterior de aquella, aunque justo a extramuros: 2 en el corte H22, y 3 de ellos en el H23. En los cortes restantes excavados en el yacimiento no ha sido localizado ningún otro fragmento de cerámica campaniforme. Desde esta perspectiva, parece claro que esta vajilla está concentrada exclusivamente en el centro espacial del poblado. Y no parece deberse a un factor temporal o cronológico. Por ejemplo, según los análisis radiocarbónicos efectuados hasta el momento, la cabañas tipo B del H22 y K-7 (cabañas situadas en el centro y periferia del asentamiento, respectivamente) arrojan unas fechas prácticamente similares. Tanto las cabañas de la primera fase del poblado (tipo A) como las del segundo momento (tipo B) están distribuidas por gran parte del área que ocupa el poblado, como indican los restos exhumados. Incluso, para el momento que nos ocupa, la segunda fase de ocupación, de finales del Calcolítico, hay casos concretos que apoyan una ocupación de la extensión total del poblado. Por ejemplo, en la zona periférica del asentamiento (corte U7) se ha documentado el uso de unas técnicas hidráulicas para hacer factible la ocupación doméstica sobre una zona anegada (Hurtado 2004: 152). Sería innecesario el empleo de tales técnicas en una zona alejada del núcleo del poblado, si la población se redujese al espacio central y, además, no hubiese problema alguno de espacio, que obligue a la ocupación de áreas poco apropiadas para actividades domésticas.

Por el momento, y según los datos disponibles, parece más probable que la distribución de la cerámica campaniforme responda a algunos factores sociales. Además, el hallazgo de un gran elenco de peculiares objetos muebles, casi de forma exclusiva, en aquellas cabañas donde aparece cerámica campaniforme -tales como instrumentos metálicos (puñales de cobre, puntas tipo Palmela, agujas o punzones), utensilios de hueso (placas, agujas y otros objetos de adorno, pequeños recipientes decorados), elementos líticos (puñal, vasos de mármol, ídolos de caliza, placas de arquero)- no parece casual.

Igualmente, en los asentamientos más extensamente excavados de la región, la cerámica campaniforme aparece fundamentalmente también en el área central. Así se documenta también en los poblados de La Pijotilla (Hurtado 1999: 53), de Porto das Carretas (Tavares y Soares, información personal), de Perdigões
(Lagos y otros 1998: 107), de Monte do Tosco (Valera 2000; 2002), de Monte da Tumba (Tavares y Soares 1987) y de Porto Torrão (Arnaud 1993: 46). Hay que anotar que para dos de estos asentamientos, La Pijotilla y Monte do Tosco, sus arqueólogos han apuntado una posible reducción del espacio ocupado en la fase calcolítica final, lo que de alguna forma explicaría la concentración de campaniforme en las áreas centrales (Hurtado 1999: 53; Valera 2000: 48). Sin embargo, estas reducciones del espacio habitado no pueden confirmarse de forma absoluta con base en la estratigrafía. Posiblemente incluso se necesitasen nuevas excavaciones para aclarar este asunto. El campaniforme se había tomado como fósil director del Calcolítico Final en contraposición a su propia ausencia para determinar una supuesta época precampaniforme. De este modo, y sólo con base en la distribución superficial de estas cerámicas, se propuso dicha disminución del área ocupada en La Pijotilla. Aparte de la necesidad de datos estratigráficos para confirmar esa hipótesis, actualmente sabemos que en otros asentamientos próximos el campaniforme se limita a las áreas centrales de los asentamientos aún cuando el resto de áreas siguen estando ocupadas. En definitiva, simplemente anotamos que la reducción del espacio habitado en el asentamiento de La Pijotilla no puede confirmarse con los datos disponibles actualmente, y que incluso se podría pensar en que esta diminución del poblamiento no hubiese ocurrido, tal y cómo documentamos en la mayoría de asentamientos excavados en extensión en la región, máxime si tenemos en cuenta la importancia del asentamiento de La Pijotilla como indica, entre otras cosas, el abundante repertorio del material arqueológico de este sitio fechado en fases avanzadas del Calcolítico.

Por otro lado, el caso de Monte do Tosco tampoco está exento de problemas. Las estructuras de la segunda fase, del Calcolítico final, que se excavan se limitan prácticamente a una cabaña circular con zócalo de pizarras donde se encuentran los restos de 32 recipientes campaniformes. Sin embargo, se han recogido restos de otros 6 recipientes en el área perimetral, aunque básicamente en estratos de derrumbe o de escorrentía sobre los niveles de la primera fase (Valera 2000: 43). Ello lleva al arqueólogo a sugerir un periodo de abandono y una ocupación posterior del sitio, si bien parece que la cabaña de zócalo de piedras, Ambiente 1 del Sector 1, se asienta directamente sobre los niveles anteriores de la primera fase (Valera 2000: 48). Sea una reducción del espacio habitado o el producto de una reocupación menos densa en época posterior, debemos recordar que todas las cerámicas campaniformes son de los grupos inciso y liso, que deben adscribirse a la última fase de 
este fenómeno con las consecuencias que esto conlleva y que serán expuestas en el apartado interpretativo.

Por último, debemos mencionar el caso de Porto Torrão. En las últimas intervenciones realizadas en el sitio, se han encontrado cerámicas campaniformes en zonas perimetrales del poblado, lo que ha servido de apoyo a uno de los arqueólogos para poner en entredicho la relación directa del campaniforme con la zona nuclear del poblado (Valera 2006: 197). Pero estos fragmentos disidentes, en lo que a su ubicación espacial se refiere, aparecen en uno de los fosos que delimitan el poblado. Según la hipótesis que plantearemos adelante, donde el campaniforme se entiende como un bien de prestigio exclusivo de los sectores política y económicamente dominantes de la sociedad, creemos que muy probablemente estas estructuras de recinto como murallas y fosos podrían haber sido objeto de ensalzamiento o veneración en momentos de su construcción, reparación o sustitución, o más bien de estrategias políticas en un amplio sentido, mediante las cuales el sector dominante sellaría el poder sobre las mismas y aglutinaría bajo una misma identidad al conjunto de la sociedad, asentando y consolidando así su propia posición de liderazgo. El hallazgo de cerámicas campaniformes en algunas de estas estructuras delimitadoras no es sorprendente ni contrasta con nuestra hipótesis como lo haría, por ejemplo, un descubrimiento reiterado de estas cerámicas en cabañas domésticas situadas en la periferia del poblado.

La distribución mayoritaria del campaniforme en estructuras de habitación en las áreas nucleares de los asentamientos indica, a nuestro juicio, una cerámica de uso exclusivo para una determinada parte de la sociedad. El núcleo central de los poblados suele corresponderse con el lugar de residencia del sector social dominante, de donde proceden los clanes dirigentes, tratándose pues de lugares con alta relevancia política $\mathrm{y}$, posiblemente, religiosa.

\subsection{Los enterramientos}

\subsubsection{Escala macro-territorial}

Los sitios de enterramientos son escasos, reduciéndose sólo a 10 casos exclusivamente funerarios y, además, a otros 4 que comprenden contextos tanto domésticos como de necrópolis. Los primeros son los siguientes: Monte das Pereiras, Monte do Outeiro, Casas do Canal I, Estremoz 10, Dolmen de Lácara, Anta de Bencafede, Barbaño, Zayas, Guadajira y Dolmen 1 da Herdade de
Carneiro. El segundo grupo comprende los sitios de San Blas, La Pijotilla, Perdigões y Escoural.

Prácticamente la mayoría de las localizaciones se sitúan cerca de recursos hidrográficos, quizás debido a la supuesta cercanía de estos enterramientos respecto a lugares de hábitat. No sabemos con precisión para todos los casos la topografía y la unidad geomorfológica sobre la que se asientan estos enterramientos. Algunas excavaciones se realizaron hace bastantes años, y las publicaciones no precisan normalmente aquellos aspectos topográficos que actualmente gozan de mayor atención. No obstante, con base en los casos donde sí se puede recoger esa información, predominan las localizaciones en territorio llano de la cuenca del Guadiana, aunque normalmente situadas sobre lomas y cerros de mayor altura. Los casos relativamente distanciados del río Guadiana y situados sobre tierras de mayor altura son Casas do Canal I y Zayas, que parece tratarse de una necrópolis.

La cerámica campaniforme documentada en contextos funerarios aparece en sepulturas circulares ( 2 casos), tholoi (al menos 2 casos) y, mayormente, en dólmenes (5 casos). Una descripción sobre estos contextos se realiza en el apartado siguiente.

Aunque el registro campaniforme funerario no es muy amplio, pueden considerarse algunos aspectos. Se evidencia una clara ausencia de un modelo de enterramiento o de ritual funerario único. La variabilidad existente entre las estructuras de enterramiento y entre las asociaciones de los diversos tipos de recipientes y de los complejos decorativos parece indicar una cierta heterogeneidad entre las manifestaciones funerarias de esas sociedades. Parece pervivir la tradición de enterramientos colectivos bajo túmulos, generalmente extendida a lo largo de la Península Ibérica y gran parte de la región occidental europea campaniforme durante todo el Calcolítico o, en términos académicos europeos, el Neolítico. Ahora bien, dentro de la concepción del enterramiento tumular colectivo parece haber una evolución hacia la construcción de estructuras cada vez menores que, finalmente, desembocan en los enterramientos individuales en cistas del Bronce Inicial. La progresiva reducción en la arquitectura funeraria se refleja mediante la documentación de diversas estructuras tipo tholos y otras estructuras menores como las sepulturas circulares. Asimismo, dentro de los enterramientos colectivos que se construyen en este periodo se evidencian ciertas tendencias novedosas, tales como una cierta individualización de los ajuares $y$, a veces, una diferenciación entre los miembros de un mismo grupo mediante objetos singulares, ambas visibles en las tumbas de La Pijotilla (Hurtado 1995: 69-70). También parece constatarse 
en algunos sitios una pérdida de interés en la construcción de monumentos funerarios (Hurtado 1995: 74), y se reutilizan por tanto otros correspondientes a momentos anteriores, donde normalmente la nueva deposición funeraria tiene un carácter individualizado, como ilustra por ejemplo el caso de Casas do Canal I.

Aunque el número de contextos funerarios de esta época en la CMG es escaso para corroborar cualquier propuesta, es interesante destacar que tanto los tholoi como las sepulturas circulares con cerámicas campaniformes se encuentran exclusivamente en la margen izquierda del río (territorio español). En contraposición, en la margen derecha (territorio portugués) los hallazgos campaniformes en contextos funerarios se limitan a estructuras dolménicas. En cambio, esta dicotomía no existe en el Bajo Guadiana, pues se conocen estructuras tipo tholos con campaniforme en ambas márgenes del río: Monte do Outeiro y Monte das Pereiras en el lado occidental y La Zarcita en el oriental.

¿Qué consideración merece esta dicotomía en la distribución de unos y otros tipos de tumbas en el Guadiana Medio? En ambas zonas se documentan dólmenes más antiguos con un repertorio material calcolítico precampaniforme. Sin embargo, no deja de sorprender la evolución hacia estructuras megalíticas inferiores que durante la fase campaniforme parece sucederse predominantemente en la margen izquierda del río, mientras que en la región alentejana perviven de forma exclusiva las estructuras dolménicas. Quizá la arraigada tradición megalítica de la región del Alentejo Norte puede ayudar a comprender en parte esta prolongada perduración.

En definitiva, todo parece indicar a que las costumbres funerarias de estas sociedades no cambiaron bruscamente, ni mediante un modelo exclusivo. No obstante, y como apuntamos anteriormente, en la CMG se evidencia una ligera tendencia hacia la reducción de las estructuras de enterramiento. Este proceso se hace más palpable en los albores de la Edad del Bronce, donde además se produce una «individualización del espacio funerario» (Hurtado y García Sanjuán 1994: 106).

\subsubsection{Escala semi-micro}

A lo largo del lado meridional del poblado de San Blas, aunque concentrados mayormente en el sector suroccidental, han sido localizadas varias estructuras funerarias. La excavación parcial del tholos 2 muestra una estructura con cámara en falsa cúpula, destruida hasta nivel de suelo, y un corredor; además, se documenta una estructura ovalada que responde a una reutilización funeraria posterior sobre el túmulo previo, aunque no se han hallado restos de enterramientos (Hurtado 2004: 153-154). Por momento, no se ha hallado cerámica campaniforme alguna en contextos puramente funerarios en este yacimiento. No obstante, hay que apuntar que únicamente el tholos 2 ha sido excavado; sólo los niveles superficiales, con el objetivo de corroborar que estos montículos correspondían a estructuras funerarias, no habiéndose siquiera alcanzado los niveles iniciales de enterramientos.

Respecto al yacimiento de La Pijotilla, han sido documentados diversos tipos de enterramientos (Hurtado 1984: 304 y ss.; Hurtado y otros 2000). Se encuentran enterramientos en silos indistintamente en las zonas meridional y oriental del yacimiento. También se documentan dos tholoi, concretamente se trata de dos estructuras circulares excavadas en el suelo y con sendos corredores que llegan a converger físicamente (Hurtado y otros 2000, Fig. 1). Además, $3 \mathrm{~m}$ al Noroeste de los tholoi se ha excavado una sepultura circular que se encontraba construida prácticamente sobre la superficie -sólo existe una pequeña zanja circular para sustentar las láminas de pizarras que delimitan la estructura (Hurtado 1984, fig. 116). Es estratigráficamente posterior a las estructuras tipo tholos. Se halló cerámica campaniforme sólo en la sepultura circular.

En Perdigões se localiza una necrópolis en el lado oriental del yacimiento (Lago y otros 1998; Valera y otros 2000) enmarcada por uno de los fosos formando un área semicircular de unos $4.400 \mathrm{~m}^{2}$. Las estructuras funerarias documentadas son sepulcros circulares. Parecen tratarse de estructuras tipo tholos. En dos de los casos, se advierten dos cámaras geminadas mediante un corredor, dejando tres áreas espaciales de enterramiento: cámara circular, corredor y atrio circular. Otro tercero muestra una única planta de tendencia circular u ovalada. Estaba bastante afectado por las labores agrícolas. Aunque en uno de los primeros (Sepulcro 2) se han localizado elementos que claramente vienen formando parte del paquete campaniforme -botón de hueso perforado en V y lámina de oro-, no se han recogido hasta el momento cerámicas de este tipo en estratos propiamente funerarios.

Respecto al yacimiento de Escoural (Soares y Tavares 1985; Valera y otros 1983) nos interesa destacar un tholos ubicado en un cerro a $200 \mathrm{~m}$ del poblado calcolítico. Sólo se ha documentado un fragmento de cerámica campaniforme en el poblado.

Además de la ya citada tumba circular del corte 8 de La Pijotilla, se conocen otros tipos de estructuras funerarias con campaniforme. El sitio de Monte das Pereiras se trata de un monumento megalítico de cámara circular, precámara en forma de trapecio y corredor (Simões 
y Freire 1961, Fig. 1). Aunque el túmulo se encontró arrasado, los excavadores pudieron identificarlo como un tholos de falsa cúpula «tipo Almería». El monumento de Monte de Outeiro se trata de un tholos a base de lajas de pizarra en falsa cúpula (Schubart 1965; Leisner 1965). El monumento de Casas do Canal I se trata, por el contrario, de un dolmen de corredor (Leisner y Leisner 1955: 5 y ss.; Leisner y Leisner 1959: 154), aunque de reducidas dimensiones. Aunque no se tiene mucha información sobre Estremoz 10, parece que se trata de un dolmen (Bubner 1979: 143), pero la cerámica que se había tomado como de tipo campaniforme ha sido posteriormente puesta en duda (Boaventura 2000: 294). El Dolmen de Lácara (Almagro 1959) tiene un túmulo de forma elíptica de diámetro medio mayor de $30 \mathrm{~m}$ y la cámara es poligonal. El sitio de Bencafede (Cardoso y Norton 2004; Pires 1896) se refiere a un dolmen de apenas $5 \mathrm{~m}$ de longitud en la estructura pétrea. Respecto a Barbaño, se trata de una sepultura circular a base de barro y adobe y posible cubierta en falsa cúpula (Hurtado 1999: 58). Se documenta otras estructuras tipo tholos $\sin$ corredor en Guadajira (Hurtado 1985; Hurtado y García Sanjuán 1994). La cerámica campaniforme aparece sólo en la Tumba 3, pero existe otras sepulturas bastante análogas denominadas Tumba 1 y 2 . Por último, el monumento de Herdade de Carneiro 1 es un dolmen reutilizado en fase campaniforme.

\subsection{Análisis sincrónico de la distribución espacial campaniforme}

Tras la recopilación y clasificación de todas las piezas cerámicas campaniformes del marco territorial de estudio, se ha procedido a la elaboración de un mapa que muestra la distribución geográfica y cuantitativa de este material - proporciones relativas de los distintos complejos decorativos en relación al total de la cerámica campaniforme documentada en cada yacimiento-(Figura 2).

Según muestra esta ilustración, la mayoría del registro cerámico aparece en sitios ubicados en torno al curso del Guadiana o, lo que es lo mismo, próximos a la línea vertebral conformada por los asentamientos de mayor tamaño. No sólo disminuye el número de sitios con este material a medida que nos alejamos de dicho eje, sino que también desciende la cantidad de cerámica. Y es que resulta que son estos asentamientos principales los que disponen de mayor cantidad cerámica y, asimismo, de más variabilidad decorativa y estilística. En cambio, en los poblados periféricos frecuentemente se encuentra un único registro campaniforme; raramente sobrepasan la cifra de dos o tres ejemplares.
Además, casi en plena totalidad de estos sitios sólo se documentan cerámicas de un único complejo decorativo, generalmente el Inciso.

Por tanto, el registro muestra claras evidencias para considerar aquellos asentamientos principales como sitios con funciones distintas, como veremos posteriormente, seguramente relacionados con la organización territorial. En lo que respecta a la cerámica campaniforme, coincidimos con A.C. Valera cuando considera estos asentamientos como filtros en la distribución de patrones decorativos y en la transferencia de productos exógenos a nivel transregional (Valera 2006: 174-176).

La promoción selectiva del campaniforme va más allá. No sólo existen fuertes diferencias entre los sitios donde aparece, sino que la difusión se produciría mediante cauces bastante rígidos y selectivos si tenemos en cuenta la gran cantidad de asentamientos coetáneos sin ningún tipo de estos materiales (ver Hurtado 2000, Figura 1). En definitiva, pensamos que la distribución del campaniforme en el área estudiada materializa estrategias de algún tipo, seguramente de naturaleza social y política, estrechamente vinculada con el tipo de relaciones entre los asentamientos de un territorio.

En contextos de poblados, los tipos cerámicos más comunes en el fenómeno campaniforme-vaso, cuenco y cazuela- aparecen mayormente, al margen de los descontextualizados o de ubicación indeterminada, en estructuras de cabañas y, algunos casos, en estratos relacionados a estructuras de fosos.

Respecto al registro funerario, aunque el número de sitios documentados en la actualidad es reducido, y teniendo en cuenta sólo aquellos fragmentos cerámicos que se pueden adscribir a un tipo de recipiente concreto, es interesante destacar que las cazuelas se vinculan con los dólmenes mientras que en cambio no han aparecido en el interior de los tholoi. El cuenco se ha documentado en tholoi y en tumbas circulares. El vaso es el recipiente con mayor frecuencia, apareciendo en todos los tipos de enterramientos.

Pueden resultar interesantes las diferentes combinaciones entre los tipos de recipientes en los contextos de enterramientos. Salvo en el caso del monumento megalítico de Herdade de Carneiro 1 -con cazuela-, en todos los demás enterramientos se documenta el vaso. A veces este recipiente se encuentra de forma exclusiva, sin ningún otro tipo cerámico campaniforme, como en los casos de los tholoi de Guadajira, de Monte de Outeiro y de Monte das Pereiras. Los tres casos son estructuras similares de enterramiento. Otras veces, el vaso se combina con la cazuela, como en Barbaño, Anta de Bencafede y Casas do Canal I. A excepción del primero de ellos que parece tratarse de un tholos, son enterramientos en 


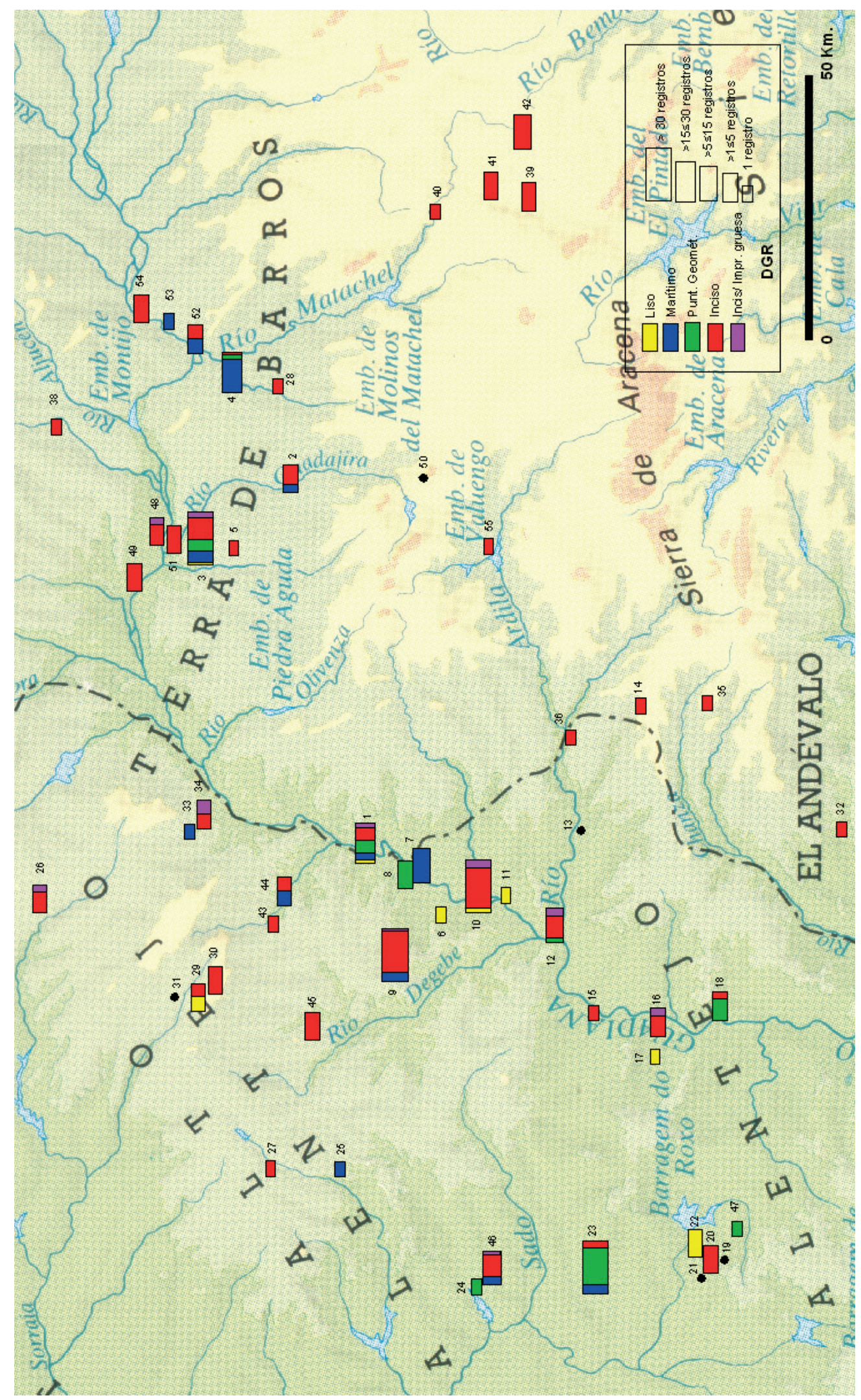

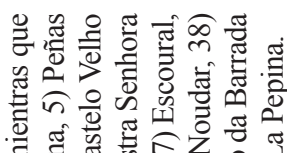

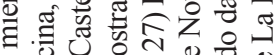

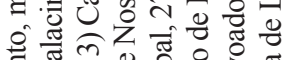

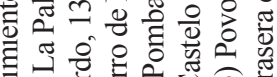

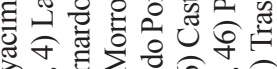

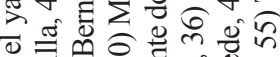
वे.

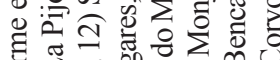

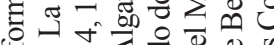

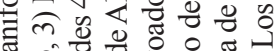

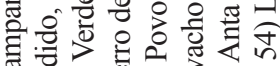

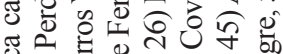

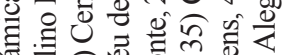
ซั ष

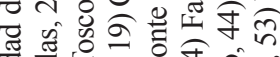

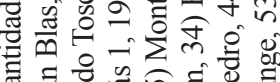

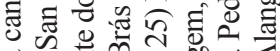
늠

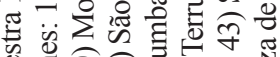

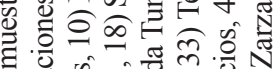
vo

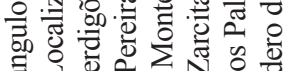

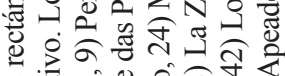

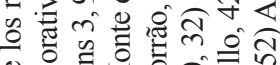

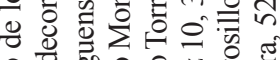

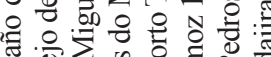
苛 可 ㅇํㅇ

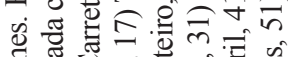
范

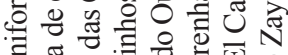

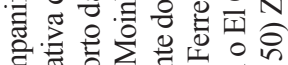
हु 눙

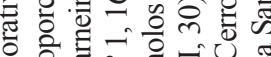

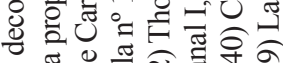
फ $\frac{\pi}{\pi} \frac{\pi}{\pi}$ สิ

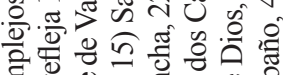

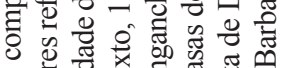

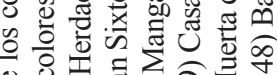

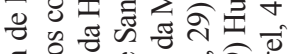
है की

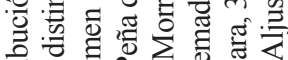

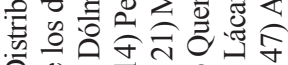

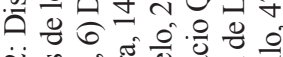

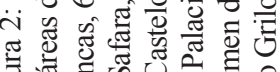

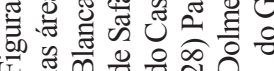

ISSN: 1133-4525 ISSN-e: 2255-3924 
estructuras dolménicas. A este respecto puede apuntarse el caso anteriormente citado de Herdade de Carneiro 1, donde aunque no aparece el vaso sí se documenta una cazuela campaniforme lisa ${ }^{2}$. Por último, existe una asociación de vaso y cuenco que se encuentra en una estructura funeraria tipo sepultura circular de La Pijotilla. En esta ocasión se trata de un cuenco sin decorar pero con un ónfalos en la base. La asociación exclusiva entre vasos y cuencos parece minoritaria, conociéndose sólo el caso de La Sarteneja, aunque puede tratarse de una falsa apariencia debida al carácter de la muestra de estudio.

Los complejos decorativos campaniformes que predominan en contextos cerrados de enterramientos son el grupo inciso y el liso. Ambos aparecen indistintamente en todos los tipos de enterramientos, pero es interesante destacar que el de tipo liso se encuentra casi exclusivamente en la margen derecha del Guadiana, en territorio portugués, a excepción de un único hallazgo procedente de la tumba circular de La Pijotilla. A este respecto, en uno de los trabajos de L. Salanova se anota que de los seis contextos funerarios con cerámicas campaniformes conocidos en el Alentejo, cuatro de ellos sólo presentan la variante sin decoración, $\mathrm{y}$ concluye que esta variante tiene menos connotaciones desde un punto de vista cultural y simbólico que los tipos clásicos decorados del litoral portugués (Salanova 2000a: 388). Tenga o no menor contenido cultural y simbólico (suponiendo que se basa en la inexistencia de la carga decorativa), no hay que pasar por alto la correlación anterior, por la que la mayoría de recipientes en contextos funerarios alentejanos son de tipo liso, a excepción de algunos ejemplares incisos presentes en dos de los enterramientos.

Sí resulta llamativo que sólo se ha documentado un recipiente de tipo Marítimo en estratos funerarios -en la sepultura circular de La Pijotilla-, y que el grupo Puntillado Geométrico no tiene representación alguna. Esto parece confirmar que la acepción funeraria del campaniforme en la región no fue tan importante como las de naturaleza política y social, quedando manifiesta en escasos contextos tardíos.

\subsection{Análisis diacrónico de la distribución espacial campaniforme}

Como decíamos anteriormente, la distribución geográfica y la frecuencia proporcional de estos recipientes

2. El campaniforme liso parece vincularse mayormente a contextos funerarios, lo que recuerda en parte al denominado "horizonte de Ferradeira" de Schubart (1971). son indicativas a la hora de rastrear la difusión de estos materiales. Por ejemplo, en el yacimiento hipotético A se documenta el 50\% de la cerámica estilo X. En el yacimiento hipotético $\mathrm{B}-\mathrm{el}$ más próximo físicamente a $\mathrm{A}$ se documenta el $25 \%$ del mismo estilo cerámico. En el yacimiento hipotético $\mathrm{C}$-más lejos de $\mathrm{A}$ que de $\mathrm{B}$ y más cerca de $\mathrm{C}$ que de $\mathrm{D}$ y E- se documenta un $15 \%$, y en los yacimientos hipotéticos D y $\mathrm{E}$-los más lejanos a A-, 7\% y $3 \%$, respectivamente. Según las relaciones geográficas y los porcentajes de material, se entendería lógicamente que el foco originario del estilo cerámico $X$ es el yacimiento $\mathrm{A}$; y que desde ese lugar se difunde a $\mathrm{B}$, y posteriormente a $\mathrm{C}$, para luego pasar a $\mathrm{D} y$, en último lugar, a E (Figura 3). Posteriormente, este modelo de distribución debe corroborarse con datos de fechas absolutas.

Este modelo parece apropiado, al menos, con las formas de distribución e intercambios de productos de alto valor, bien de prestigio, simbólico, etc., donde a nuestro juicio se encuentra la cerámica campaniforme. Esta premisa teórica y modelos similares han sido planteados por diversos autores. Por ejemplo, habría que recordar el trabajo de D.L. Clarke sobre las redes económicas y sociales mediante las que se divulgan estos elementos (1976). Realmente, el modelo básico planteado comparte similitudes con el desarrollado por este autor (Clarke 1976: 464-468, Figuras 3-5), y hay que relacionarlo en parte, también, con los modelos de "World System" y "Centro-Periferia" que se han venido aplicando al panorama arqueológico.

La única objeción de partida en este modelo es que la distribución de la cerámica campaniforme en el territorio respondiese al producto final de un sin fin de difusiones multi-direccionales, con varios sentidos de marcha. En principio, con un razonamiento básico podríamos empezar adoptando un proceso homogéneo de este tipo, como un todo, para la difusión del campaniforme. De hecho, no se descartan algunos contextos donde varios complejos decorativos hubieran llegado simultáneamente, e incluso podríamos llegar a pensar que los diferentes complejos no conforman barreras inflexibles. A este respecto, se documentan algunos ejemplares mixtos, a caballo entre uno y otro grupo decorativo. Pero por el contrario, hay ciertos factores fundamentales que chocan frontalmente con un proceso de difusión homogéneo del campaniforme, y que hacen pensar más bien en que las difusiones de los diferentes grupos decorativos no deben haber ocurrido todas a la par.

En primer lugar, y en referencia a la dimensión cronológica, se viene argumentando una cierta antigüedad del Marítimo respecto al Puntillado Geométrico, y de éste último respecto al Inciso (Soares y otros 1972; Farinha y otros 1972: 182-183; Cardoso 2001: 145; Kunst 


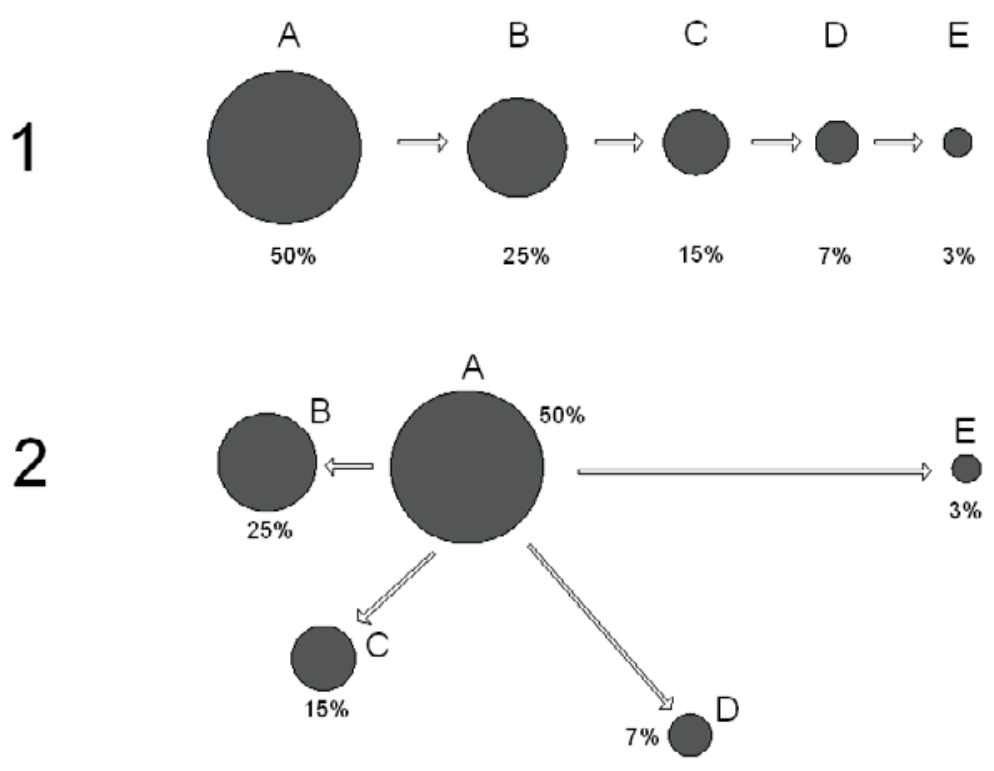

Figura 3: 1) Gráfico ilustrando una difusión lineal o en cadena. 2) Gráfico ilustrando una difusión radial a partir de un centro.

2005: 198-199). Generalmente, se cree que las cerámicas de tipos cordados son las más antiguas dentro del fenómeno campaniforme, apoyándose esto en la hipótesis del origen holandés. No obstante, ya hemos hecho referencia a otros estudios que defienden la antigüedad de las cerámicas impresas, y concretamente del Marítimo Internacional proponiendo su origen independiente, respecto de aquellas otras cordadas, en el estuario del Tajo (Kunst 2005: 202). Sean las impresas o las cordadas las de mayor antigüedad, es cierto que ambas aparecen en el momento inicial del campaniforme ibérico y, por tanto, son indicativas en relación al inicio de este fenómeno. A este respecto, cabe recordar el vaso CZM de La Pijotilla que conjuga la técnica cordada con la impresa, materializando los inicios del campaniforme en la zona. De forma similar, el vaso cordado de Porto Torrão no parece tener diferencia cronológica con las cerámicas marítimas que allí se encuentran.

Dentro del grupo de las cerámicas campaniformes decoradas mediante impresiones, se ha venido diferenciando otro grupo denominado Puntillado geométrico. La concepción general de la técnica utilizada en este grupo parece proceder del complejo Marítimo. En cambio, los esquemas y motivos decorativos empleados son bastante diferentes, llegando a guardar en este aspecto una relación mayor con el tipo inciso. Este grupo se desarrolla mayormente en la cuenca baja del Tajo, si bien existe una considerable distribución a lo largo de toda la zona central de Portugal y, por otro lado, en el valle del Guadalquivir.

Las diferencias de las distribuciones espacialesgeográficas entre los complejos decorativos campaniformes parecen responder fundamentalmente a razones o tradiciones culturales si nos atenemos a un marco territorial mayor que el contemplado en este trabajo. Cada uno de estos complejos se asocia o es característico, aunque no obligatoriamente exclusivo, de un área geográfica determinada. Por ejemplo, es indudable la relación del Puntillado Geométrico con el área central portuguesa, y concretamente con el estuario del río Tajo. Lo mismo ocurre con el grupo Ciempozuelos en el área meseteña ibérica. A este respecto, hay que destacar la ubicación central de nuestro territorio de estudio entre las dos grandes áreas geográficas anteriores, lo cuál puede facilitar la integración de distintos complejos decorativos.

La figura 2 muestra que las diferentes distribuciones geográficas y cuantitativas de cada uno de estos grupos distan bastante de ser idénticas entre ellas. Por tanto, parece apropiado analizar la difusión del campaniforme con base en los diferentes complejos decorativos, al 
menos en algunos niveles de la aproximación que se ha realizado en nuestro trabajo. En la CMG hay que tener en cuenta un aspecto fundamental que, incluso, pudiera tener alguna influencia en las formas de promoción y empleo de estas cerámicas. Se refiere a la gran diferencia de la distribución del Marítimo y del Puntillado Geométrico respecto a la del tipo Inciso. Mientras que los dos primeros grupos aparecen fundamentalmente en los asentamientos principales, las cerámicas incisas aparecen en un rango mucho mayor, tanto en lo que a la distribución geográfica se refiere como a la variabilidad de tipos de asentamientos donde aparece. Las cerámicas campaniformes algo más tempranas, de tipo Marítimo, aparecen, según el registro arqueológico, en los asentamientos mayores y, puntualmente, en algunos secundarios no a mucha distancia de los primeros. Algo similar ocurre con las puntilladas geométricas aunque son algo más comunes en el área alentejana. La situación cambia completamente en el caso de las cerámicas incisas. Parece ser cierto, que este grupo decorativo es algo posterior a los anteriores, si bien la pauta del desarrollo y del cambio entre estos grupos estilísticos parece responder a una sustitución proporcionalmente gradual y posiblemente no muy lenta, con una cierta simultaneidad entre ellos.

La disposición del grupo cerámico Marítimo Internacional muestra un eje longitudinal en sentido Noreste-Suroeste, solapado con el propio curso del río, y con una anchura territorial o rango espacial geográfico bastante reducido. Las fechas disponibles más antiguas que presumiblemente se puedan relacionar con los momentos iniciales del campaniforme, proceden de los yacimientos de Porto Torrão y de La Pijotilla, ambos situados prácticamente en sendos extremos del territorio que ahora se estudia. Son asentamientos claves, que juegan un papel principal en la organización del territorio, y que posiblemente son centros de dos marcos de organización política distintos. En este sentido, no sorprende que fuesen los dos asentamientos claves y vertebradores de cada uno de los territorios los que primero recibiesen el influjo de estas cerámicas. Estas fechas más antiguas para estos dos emplazamientos se corroboran con el hallazgo exclusivo en sendos yacimientos de cerámica cordada, que puede considerarse como indicador de los momentos iniciales del fenómeno campaniforme (Harrison 1980: 128; Suárez 1997). El caso del vaso de Porto Torrão tiene decoración lineal cordada, y el de La Pijotilla se adscribe al subtipo CZM, con la peculiaridad de mezclar las técnicas cordadas con las bandas impresas a peine. Por otro lado, el caso de Porto Torrão, el situado más al Suroeste de nuestro territorio de estudio, es, supuestamente, más puro que el de
La Pijotilla. Las cerámicas cordadas son bastante escasas en el ámbito peninsular ibérico. Es en el Noroeste y en el País Vasco, y en sus inmediaciones, donde parece existir una presencia clara de este tipo cerámico (Suárez 1997; Suárez y Lestón 2005: 1). Además, teniendo en cuenta las variantes cordadas, parece que el AOC aparece fundamentalmente en la periferia peninsular, concretamente en el norte de la fachada atlántica -a excepción del registro de Porto Torrão en el Sur- y el cuadrante Noreste ibérico, mientras que el CZM aparece fundamentalmente en este mismo cuadrante Noreste y a lo largo del interior peninsular (Suárez y Lestón, 2005: 18, Fig. 9).

Respecto al grupo general Marítimo, la decoración entre todos sus ejemplares es muy homogénea. Apenas si existen motivos diferentes que se destaquen en el conjunto. Difícilmente, se podrían rastrear imitaciones y copias de recipientes, ni aspectos sobre la difusión de estas cerámicas, mediante un análisis de los motivos decorativos. Las fechas absolutas relacionadas con este complejo decorativo no son numerosas. En La Pijotilla, la mayoría de registros aparecen en superficie, lo que reduce notablemente las posibilidades estratigráficas e, igualmente, ponerlos en relación directa con las fechas radiocarbónicas obtenidas en este yacimiento, que rondan mayormente el segundo cuarto del III Milenio a.C. Solo el caso del registro en estratigrafía, concretamente hallado en la tumba circular del Corte 8 , permite enlazarlo con una cronología absoluta, y debe situarse posteriormente a $4130 \pm 40 \mathrm{BP} / 1$ sigma cal: $2865-2595$ BC. No obstante, si atendemos al momento de la llegada del marítimo al yacimiento, esta fecha no es en absoluto significativa; en esta misma sepultura donde aparece el marítimo se documenta asimismo campaniforme de tipos Puntillado Geométrico e Inciso. Habría que anotar, además, otras muestras obtenidas en este yacimiento que, si bien no se relacionan en la estratigrafía de forma directa con cerámicas marítimas, retrotrae a momentos más antiguos la fecha anterior. En el sector central del yacimiento, en un contexto de cabañas y silos se obtuvo la cifra de $4010 \pm 80$ BP (1 sigma cal 2836-2375 BC, 2 sigmas cal 2865-2761). Aunque no se encontró cerámica campaniforme, si aparecieron cerámicas de paredes finas -normalmente asociadas en este territorio a momentos finales del Cobre y transición a la Edad del Bronce-, un cuchillo de cobre y un ídolo oculado en hueso. Otra datación de interés es la obtenida en el nivel intermedio del relleno del silo E4, una vez se reaprovecha éste como lugar de habitación (Beta-121146) y que arroja una fecha de $4110 \pm 40$ BP/ 1 sigma cal: 2860-2585 BC. En un estrato posterior de relleno del mismo silo aparece un 
fragmento campaniforme inciso. La fecha más antigua obtenida para La Pijotilla procede del nivel inferior de esta misma estructura, pero aún cuando cumplía la función originaria de silo, con una cifra de $4360 \pm 50 \mathrm{BP} / 1$ sigma cal: 3030-2905 BC.

En el asentamiento de San Blas, dos de los fragmentos pertenecen al corte J-27, sobre el cual aún no se ha realizado ninguna fecha absoluta. No obstante, la similitud en diversos aspectos de esta estructura de cabaña con las documentadas en los cortes H-22 y K-7 lleva a situarla en un periodo no muy distante. Las fechas obtenidas en ambas cabañas se colocan justo en la mitad del III Milenio a.C. En Porto das Carretas, las fechas radiocarbónicas para estos momentos rondan el tercer cuarto del III Milenio a.C. (Tavares da Silva y Soares, información oral). En Porto Torrão, las fechas radiocarbónicas proceden de muestras óseas de fauna recogidas en la intervención de 1982, concretamente recogidas en los estratos 1 y 2 , de donde proceden sólo tres de los registros marítimos. Las fechas rondan las cifras centrales de la primera mitad del III Milenio a.C, aunque una de ellas parece algo más reciente, situándose próxima al ecuador de dicho milenio.

En segundo lugar, el Puntillado Geométrico se encuentra mayormente en torno al estuario del Tajo, donde se engendra el denominado "complejo Palmela", y en el valle del Guadalquivir, donde diversos estilos campaniformes se mezclan con características propias locales, en una fase tardía, hasta conformar el denominado "complejo de Carmona" (Lazarich 1999: 705). Ahora bien, el apelativo de Puntillado Geométrico define un grupo mayor que sobrepasa los límites de los estilos manejados hace una veintena de años. Aparte de recipientes menos comunes como cuencos con pié ("fruitstand type" de Harrison 1977), el complejo Palmela se refiere fundamentalmente a cuencos y cazuelas (generalmente a formas abiertas) que se decoran mediante motivos geométricos impresos. En cambio, el concepto de Puntillado Geométrico engloba todos aquellos tipos cerámicos que se realizan mediante estas mismas decoraciones impresas -fundamentalmente líneas en zig-zags, triángulos y rombos- donde es frecuente encontrar otros recipientes acampanados de cierta talla como vasos ${ }^{3}$.

3. Francamente, los nombres de estilos o tipos campaniformes manejados han dependido de los criterios que los investigadores han primado en sus clasificaciones. Algunos acuñaron términos con base en las técnicas utilizadas, otros a tenor de los motivos decorativos dominantes; en otros casos, algunas clasificaciones han mezclado conceptos de una y otra clase, hasta el punto de que resulta imposible compatibilizar diferentes estudios de diferentes regiones. Esta situación de confusión en cuanto a la definición de grupos ha sido anotada en algunos trabajos (Lazarich 1999: 706-707). Por tanto, en nuestro
El Puntillado Geométrico tiene una distribución similar al Marítimo, si bien parece tener un rango espacial algo mayor en el Alentejo. Son tres los yacimientos que disponen de dataciones absolutas relacionadas estratigráficamente con estas cerámicas: Porto Torrão, San Blas y La Pijotilla. Las fechas más antiguas proceden de Porto Torrão, mientras que las referentes a San Blas y La Pijotilla difieren muy poco entre ellas. En Porto Torrão, las dataciones provienen de los estratos 1 y 2 , donde se habían documentado también 3 registros marítimos. No hay aquí, por tanto, diferenciación cronológica absoluta alguna entre ambos grupos decorativos. Ahora bien, la excavación realizada en el 2003 sí corrobora la evolución normal (Internacional $>$ Puntillado Geométrico>Inciso) en las proporciones de estos grupos a lo largo de las 4 fases documentadas en el sitio.

En San Blas tenemos datado un momento algo anterior al 2550-2300 BC. Son las dataciones procedentes del corte $\mathrm{H} 22: 3950 \pm 40 \mathrm{BP}$ y $3930 \pm 40 \mathrm{BP}$ que calibradas a 2 sigmas toman unos valores de Cal BC 2550-2540 (Cal BP 4500-4480) y Cal BC 2490-2300 (Cal BP 4440-4250). Esta muestra procede del estrato 29 , de la segunda fase de ocupación, mientras que la pieza puntillada proviene del estrato 64 , de la primera fase, con lo que hay que tomarla como algo anterior.

En La Pijotilla, se cuenta con una fecha algo posterior a 2865-2595 BC. Esta referencia cronológica responde a un fragmento de la Tumba 8 , la misma estructura en la que se encontró el único fragmento marítimo en estratigrafía, con lo que la situación a nivel de cronologías absolutas es idéntica, aunque francamente vaga.

Aunque tanto esta última fecha de La Pijotilla como aquellas otras aún más altas -pero sin relación estratigráfica con las piezas puntilladas- parecen indicar una importación temprana -y posiblemente directa desde el estuario del Tajo- de estas piezas, sorprende la falta de estos materiales en los yacimientos situados al Este del Alto Alentejo. Parece quizá más probable que la introducción del Puntillado Geométrico se realizase desde el Suroeste de nuestro territorio, donde existe la datación absoluta más alta de un estrato cerrado, y donde es mucho más abundante, tanto en términos totales como en proporcionales. Algunas de las características de este grupo se corresponden fundamentalmente con el complejo Palmela que Harrison asociaba al centro de Portugal (1977: 17-19 y 48). Es muy probable que esta cerámica, o esta influencia, se extendieran desde el estuario del Tajo hacia el área alentejana mediante el curso del río Sado, donde se encuentra Porto Torrão. Desde este

estudio se acepta el término amplio de Puntillado Geométrico, que anula ciertas ambigüedades. 
emplazamiento se difundirían a yacimientos secundarios de esa misma región -como los casos de Aljustrel y São Brás 1- y a otros situados a mayor distancia. Pero estos últimos casos son escasos; se limita prácticamente a los yacimientos claves en la ordenación del territorio. En este último caso, estaríamos refiriendo muy seguramente una escala de transferencia entre poblados de primer orden de diferentes territorios.

Resulta interesante la representación puntual del Puntillado Geométrico en la margen izquierda del Guadiana Medio. Es el grupo campaniforme menos representado. Incluso las cerámicas marítimas parecen tener mayor difusión.

Mediante un análisis de motivos decorativos (con secuencias codificadoras de la decoración) la información extraída de interés no es muy amplia, sino más bien puntual e inconclusa (debido fundamentalmente al alto grado de fragmentación del conjunto cerámico) y habría que tomarla pues con la debida cautela. Algunas figuras geométricas como el triángulo y el rombo son muy comunes en el grupo denominado Puntillado Geométrico. Estas formas se repiten frecuentemente en las cerámicas de todo el territorio que ahora estudiamos. Sin embargo, pueden trazarse algunas diferencias estilísticas entre algunos de ellos. Los motivos o rellenos de estas figuras geométricas difieren, según los ejemplares conocidos hasta el momento, en algún sentido si comparamos la zona alentejana portuguesa con el resto del territorio que aquí se estudia. Los rellenos de los triángulos de las cerámicas de los sitios de Porto Torrão y de Aljustrel se realizan a base de líneas puntilladas impresas paralelas entre sí, y en cualquier sentido -horizontal, vertical y oblicuamente-. Sin embargo, las demás cerámicas puntilladas geométricamente distribuidas por toda el área restante de nuestro territorio muestran un repertorio más limitado en cuanto a los motivos o rellenos de los triángulos se refiere, pues se realizan fundamentalmente a base de líneas impresas paralelas horizontales, apenas un par de casos en vertical, pero en ningún ejemplar de forma oblicua. Sin embargo, esta sutil diferencia parece restringirse al grupo Puntillado Geométrico, ya que los rellenos de los motivos decorativos del grupo Inciso muestran mayor variabilidad. Es cierto que el Puntillado Geométrico está más representado en la zona alentejana que en el resto del área de estudio, por lo tanto esta variabilidad mayor en los motivos decorativos pueda responder a la mayor proporción numérica de esas cerámicas. De todas formas, no deja de resultar interesante que los rellenos en sentido oblicuos no aparezcan en las cerámicas puntilladas geométricamente de toda el área restante. Parece entonces que la elaboración de recipientes puntillados en toda esta área reprodujese sólo algunos modelos de los existentes en la supuesta zona alentejana, de alguna forma, el primer foco difusor de este grupo cerámico en la región estudiada.

Aparte de este proceso que no difunde exactamente todo el sistema decorativo de la zona originaria, se podría sugerir otro por el cual se añaden nuevos motivos en la zona receptora. Concretamente, se refiere al uso de puntillados gruesos que acompañan a los de tipo fino mediante peine, concha, ruleta, etc. Esto se constata en algunos ejemplares procedentes de San Blas y de La Pijotilla. Por tanto, en el área de la margen izquierda del Guadiana, en el proceso de reproducción de modelos cerámicos procedentes de la zona alentejana, se podrían haber incorporado asimismo nuevos motivos presumiblemente de tradición local. De hecho, los motivos mediante la técnica de puntillado grueso son bastante comunes en esta zona. Además de su existencia en la cerámica campaniforme, fundamentalmente en el grupo Inciso, abunda en otros géneros cerámicos, como en el grupo de la cerámica decorada no campaniforme.

En lo que respecta a las formas de los recipientes del Puntillado Geométrico, se observa una tendencia clara en los datos: los cuencos predominan en el área suroccidental del territorio estudiado -Alentejo-, fundamentalmente en el sitio de Porto Torrão, mientras que el resto de tipos se difunde con regularidad.

Por último, en lo que respecta al contexto de estas cerámicas, y de forma similar al Marítimo, casi todos los registros en estratigrafía proceden de ambientes domésticos. Aparte de los descontextualizados y los de procedencia indeterminada, la mayoría (30 casos) provienen de cabañas, escasamente de fortificaciones (3 casos) y sólo un ejemplar de contexto funerario.

En tercer lugar, la cerámica campaniforme de tipo Inciso que ha sido siempre puesta en relación con el grupo meseteño conocido como Ciempozuelos. Estas cerámicas incisas caracterizan el conjunto campaniforme de esta región, pero se encuentran abundantemente en otras muchas zonas geográficas. Aparecen en la mayoría de los restantes complejos o grupos campaniformes de la Península Ibérica.

En cuanto se refiere a la región del Guadiana Medio y Bajo, este grupo de cerámicas es el más numeroso en términos globales. Pero además se extiende por un número mucho mayor de yacimientos que el resto de estilos. Como ya se había apuntado anteriormente, el rango territorial que alcanza el grupo inciso es muy amplio, y engloba tanto grandes yacimientos, como pequeños emplazamientos, y también contextos funerarios. En definitiva, la aceptación, o más bien, la accesibilidad a este tipo cerámico inciso es mucho más abierta y asequible que en los otros grupos decorativos. Su uso no 
parece tan restringido, lo que puede indicar una relativa apertura de estos objetos en un momento avanzado del fenómeno campaniforme.

A modo de conclusiones, el campaniforme inciso tiene una amplia difusión geográfica en el territorio estudiado. El grueso de su distribución parece concentrarse a lo largo del mismo río Guadiana, como indican las localizaciones de la región de Mérida, las situadas en el área septentrional de Tierra de Barros -en torno al sitio de La Pijotilla-, y las ubicadas desde la región de Olivenza ocupando todo el curso del río allí donde ambas orillas son portuguesas. Aquí, el sitio más meridional hoy conocido es São Brás 1. No obstante, esta distribución no se limita a estas regiones. Existen localizaciones lejanas del río principal, aunque por regla general junto a vías fluviales secundarias. Muchos de ellos son emplazamientos ubicados tierra adentro, situados fuera del supuesto eje principal de ordenación territorial, pero que pueden haber tomado parte en una vertebración secundaria - a otros niveles inferiores- del territorio.

Poco se puede anotar sobre el sentido de la difusión de estos objetos. Las escasas fechas absolutas conocidas hasta el momento no facilitan en absoluto esta cuestión. Solo los yacimientos de La Pijotilla, Escoural, San Blas y Porto Torrão y Palacio Quemado arrojan algunas fechas. Las fechas más altas corresponden a Porto Torrão y a La Pijotilla, siendo bastante similares entre ellas. En el caso de Porto Torrão, las fechas radiocarbónicas de interés proceden de los estratos 1 y 2 de las intervenciones de 1982, y fueron ya anotadas en el apartado de las cerámicas marítimas. Se sitúan básicamente en la primera mitad del III Milenio a.C (Arnaud 1993: 46). Ahora bien, la representatividad inferior del grupo inciso (2 registros) respecto a los demás hace pensar en que se tratase de un momento no excesivamente tardío, que posiblemente se pueda corresponder a la Fase 3 presentada tras las excavaciones más recientes. La existencia de un registro mixto - a base de impresiones a peine e incisiones- en esos estratos pudiera corroborar lo anterior. Por tanto, el momento más representativo del grupo inciso sería posterior a lo que indican esas fechas. En La Pijotilla, el registro inciso en estratigrafía se halla concretamente en el Estrato $\mathrm{V}$ del Corte 14. La única información a este respecto procede de una fecha absoluta de un estrato anterior: $4110 \pm-40 \mathrm{BP} / 1$ sigma cal: $2860-2585 \mathrm{BC}$, lo que fija un post quem para el registro inciso.

Algo más recientes parecen aquellas otras procedentes de los poblados de Escoural y de San Blas. En el primero de los asentamientos, desconocemos la procedencia concreta del fragmento inciso en estratigrafía, aunque se sabe que procede del nivel II de ocupación de la zona de hábitat (Soares y Tavares da Silva 1985: 78). Existen unas muestras de huesos que parecen datar varias fases del poblado. Según el arqueólogo, datan un Calcolítico Medio (3090-2590 BC y 2910-2410 BC, a 2 sigmas), y otras dos datan un momento más reciente (2870-2210 BC y 2850-2140 BC, a 2 sigmas) (Gomes 1991; Gonçalves y Catarina 2000: 74). Quizá, el estrato donde aparece el ejemplar inciso se relacione más bien con éstas últimas fechas, aunque la información publicada no permite precisar a este respecto. Por otro lado, en San Blas, existe una muestra procedente del estrato 29 , anterior a aquellos donde se recogen las piezas incisas, que arroja unas fechas de $3950 \pm 40$ y $3930 \pm 40 \mathrm{BP}$, una vez calibradas a dos sigmas: 2550 a 2540 y 2490 a 2300 BC Cal. De este modo, la datación concreta de las piezas incisas es posterior a estas fechas. Las piezas incisas documentadas en el corte H23 también aparecen en los estratos superiores, denotando el momento tardío de este grupo decorativo. Para el caso del corte J27, ya se ha anotado la situación igualmente tardía que refleja el grupo inciso, que aparece sólo en la tercera y cuarta subfases de la cabaña.

La fecha más reciente se refiere a la procedente de Palacio Quemado. Aunque la muestra no parece proceder del estrato donde se encuentran estas cerámicas, fecha la segunda fase del poblado: 1620 AC (3570 \pm 100 B.P.), según creen los propios autores excesivamente avanzada, con lo que ven conveniente la realización de nuevos análisis para esta segunda fase (Hurtado y Enríquez 1991: 87).

Quizá el momento inicial de la difusión de estas cerámicas se produjese de forma rápida por los poblados del eje principal y, en momentos posteriores, se fuese difundiendo por otros territorios secundarios -redes de segundo orden-. Pero se necesitan dataciones absolutas, principalmente, de estos poblados secundarios. Por el momento, como se acaba de exponer, las únicas fechas disponibles a este respecto son las del poblado de Escoural y Palacio Quemado, algo más recientes efectivamente que las conocidas en los emplazamientos mayores.

Acerca del análisis de los motivos decorativos, los resultados de interés se refieren a la variante incisa que presenta algunos motivos impresos, generalmente de factura tosca, y donde destaca la "hoja de acacia" (Figura 2, color magenta). Su distribución se desarrolla sobre una cierta latitud, aunque fundamentalmente se limita al mismo curso del río Guadiana. Se ha documentado en los sitios siguientes: La Pijotilla, Barbaño, Famão, Monte Pombal, San Blas, Perdigões, Monte do Tosco, S. Bernardo y Três Moinhos. Fuera de esta área central del territorio estudiado, apenas se encuentran cerámicas con motivos de "hoja de acacia". Son los casos del ejemplar hallado en Barrada do Grilo, otro recogido en Monte do Pombal y posiblemente aquellos 
otros rescatados en Monte da Tumba, aunque éstos últimos son algo dudosos en cuanto a su adscripción definitiva al grupo campaniforme ${ }^{4}$. Sólo desde San Blas y de Monte do Tosco se pueden extraer consideraciones en cuanto a la posición estratigráfica de estas piezas, que están presentes en el momento inicial del grupo inciso. Por ejemplo, en el corte J27 de San Blas, los fragmentos incisos más antiguos, según la estratigrafía, tiene motivos impresos de este tipo. Por último, hay que apuntar que en la región de estudio el motivo de "hoja de acacia" aparece de forma exclusiva en el grupo inciso, y no en el Puntillado Geométrico sorprendentemente, dada la antigua tradición de este motivo en el estuario del Tajo, donde supuestamente surge dicho complejo decorativo.

La mayor parte de las cerámicas incisas aparecen en contextos de hábitat, en parte debido al número muy superior de poblados respecto al de necrópolis o estructuras funerarias aisladas del conjunto.

El grupo campaniforme liso ${ }^{5}$ se centra mayormente en el territorio occidental del área estudiada, tanto en el curso del Guadiana como en tierras portuguesas interiores, como indican los yacimientos de Casas dos $\mathrm{Ca}-$ nal I y Monte do Outeiro.

\section{VALORACIÓN}

En el apartado 3, referente a la historiografía y enfoques interpretativos del Campaniforme europeo, vimos que la asociación de este fenómeno con el mundo funerario ha sido puesta de manifiesto en repetidas ocasiones. Esta relación parece cierta en muchas regiones geográficas. En la CMG, en cambio, el registro cerámico campaniforme en contextos funerarios no es muy abundante, en parte debido quizás a que los enterramientos que se conservan no son muy numerosos. Sin embargo, y con cierta sorpresa respecto a lo que se podía imaginar hace dos décadas, los hallazgos en poblados y zonas de hábitat vienen siendo más frecuentes, sobrepasando actualmente la cifra de 400 ejemplares en más de 40 asentamientos. Existe una indudable supremacía

4. Quizá la presencia de este motivo en este par de yacimientos arqueológicos más alejados del Guadiana está relacionada con la propia ubicación de estos, en dirección hacia la cuenca del Tajo, donde este motivo también es muy común.

5. La distribución de este grupo cerámico habría que tomarla con cautela. Los ejemplares de este tipo no están tan bien definidos como aquellos otros de los restantes grupos. La ausencia de decoración dificulta la identificación de estos recipientes, que mayormente son adscritos cuando conservan una gran parte del mismo, que manifieste su forma acampanada, o, en el menor de los casos, cuando disponen de algunos atributos diferenciadores, como por ejemplo la presencia de ónfalos en la parte correspondiente a la base. numérica de las cerámicas en contextos de hábitat que sobre aquellos otros funerarios. Además, el reducido conjunto de estos últimos tiene una heterogeneidad muy pronunciada, según los tipos de las estructuras de enterramiento, las formas rituales o depositarias de muertos y ajuares, las variadas combinaciones de tipos de recipientes, etc. Este panorama refleja la ausencia de un modelo ritual funerario campaniforme establecido o de fuertes cambios respecto a las tradiciones anteriores. De hecho, la única tendencia uniforme que debe mencionarse es la continuidad de la tradición funeraria bajo túmulos aunque con una evolución hacia la reducción de los enterramientos y una ligera individualización de los ajuares (Hurtado 1995: 69-70). Todos estos factores señalan, en definitiva, que en esta región el fenómeno campaniforme no tuvo un sentido tan funerario, sino más bien otro vinculado estrechamente con el mundo de los vivos, lo que evidentemente no impide que en algunas ocasiones se depositasen puntualmente cerámicas de este tipo junto a determinados enterramientos.

El registro actual de la $\mathrm{CMG}$ se aviene mejor con la hipótesis del campaniforme como bien de prestigio con alto valor de intercambio, propuesta desde el congreso de Oberried (Clarke 1976; Burgess y Shennan 1976). La distribución de estas cerámicas es selectiva y jerárquica, como vimos en el apartado 4, produciéndose sólo en determinados asentamientos y, dentro de ellos, fundamentalmente en espacios vinculados a un sector reducido de la sociedad. Además, es interesante que siempre aparecen en un bajo porcentaje que en ningún caso alcanzaría el $5 \%$ del conjunto cerámico total, y que frecuentemente se asocian a otros elementos preciados de la cultura material usualmente exclusivos de esos contextos restrictos. Generalmente, las funciones básicas que se pueden desprender de este tipo de contenedores quedan indudablemente cubiertas por otros grupos cerámicos comunes dedicados al servicio cotidiano. No estamos de acuerdo, pues, con que la vajilla campaniforme tuviera un uso común en diversos contextos sociales (Salanova 1998; 2001: 98; 2005: 9; Brodie 1998) y con que se minimice su carácter exótico y su valor de prestigio debido, según argumentan algunos autores (Convertini 1996; Convertini y Querré 1998; Clop y Molist 1998; citados en Salanova 2005: 9), a la existencia de poblados campaniformes y a su procedencia desde contextos locales. Francamente, no sabemos hasta qué punto es acertado el concepto de "poblado campaniforme", al menos con base en nuestro conjunto, cuando aparecen algunos asentamientos con ciertas innovaciones en la fase campaniforme, otros sin tales cambios $\mathrm{y}$, en cambio, algunos otros donde parecen producirse esos rasgos novedosos sin la presencia de esa cerámica. Posiblemente el 
registro concuerde mejor con el carácter «extra-cultural» que C. Burgess y S. Shennan sugieren para el campaniforme, como una parte del conjunto de artefactos más que como un propio conjunto cultural (1976: 309$310)$, en el sentido de que no podría asociarse exclusivamente con ninguna sociedad o grupo cultural. Por otro lado, la elaboración local de estos objetos puede reducir o eliminar su carácter exótico, pero en absoluto tiene porqué negar su valor de prestigio.

Que la distribución de estos materiales no se produzca de manera regular sobre un territorio uniformemente poblado revela determinados patrones en su propia difusión que seguramente se relacionen con estrategias de algún tipo a nivel de grupos de asentamientos y territorios. Como veíamos en el apartado 4, el tamaño de los emplazamientos, la existencia de recintos de fosos o murallas y la complejidad de los mismos obedecen en gran parte, igualmente, a patrones territoriales. Ya se ha hecho referencia a los estudios de territorio que, desde la década de los 90, se vienen realizando en la región por parte de V. Hurtado, quien sugiere con sólidos argumentos un territorio espacialmente definido y política-religiosamente articulado en torno a $\mathrm{La} \mathrm{Pi}$ jotilla desde época precampaniforme (Hurtado 1995; 1999; 2000). Incluso la distribución espacial de los ídolos calcolíticos refleja diversas áreas estilísticas que se solapan bien con territorios de este tipo a lo largo del Suroeste peninsular (Hurtado e.p.). El análisis del fenómeno campaniforme en la CMG no debe pasar por alto el propio contexto adonde se inserta, ese entramado territorial al que nos hemos referido. ¿Qué podemos extraer poniendo ambos en conjunto?

El tipo de territorio propuesto anteriormente es apropiado para enfocarse desde el modelo "Centro-Periferia" entre los arqueólogos dedicados al análisis de las sociedades prehistóricas. Al margen de las críticas arrojadas sobre este modelo, fundamentalmente a causa de la extrapolación de sistemas económicos modernos hacia tiempos prehistóricos, resulta aquí efectivo como herramienta para rastrear niveles de jerarquías dentro del territorio. Máxime teniendo presente las cerámicas campaniformes, sujetos de nuestro estudio, como bienes de prestigio. La distribución de este tipo de materiales preciados materializa en el registro las relaciones jerárquicas del territorio mejor que cualquier otro ítem más común.

El concepto de jerarquía en el análisis de comunidades humanas dentro de un territorio lo entendemos como el nivel de relación-influencia, o de dominio-dependencia, de cada uno de los asentamientos en relación a los demás. En parte, el tamaño de los asentamientos sirve como indicador al respecto. Es interesante que el tamaño de los asentamientos se correlacione claramente con la distribución cuantitativa y cualitativa de las cerámicas campaniformes. Los que podrían denominarse con la Categoría u orden 1 tienen ejemplares de todos los complejos decorativos y, además, mayor cantidad. Son aglutinadores de gentes, de poder, de bienes. Los de Categoría u orden 2 son bastante más pequeños, relativamente próximos a los anteriores, pero pueden haber desempeñado importantes tareas de conexión con la periferia dada su situación intermedia. Los de Categoría u orden 3, el resto de asentamientos (algunos con campaniforme), son más pequeños y numerosos.

El Marítimo aparece casi de forma exclusiva en los de primera categoría; escasa y puntualmente en la Categoría 2. Sólo en una docena de sitios aparecen cerámicas de esta clase, y en la mitad de ellos sólo se han encontrado uno o dos ejemplares. El acceso a estas piezas fue extremadamente restringido. Respecto al Puntillado Geométrico, hemos de diferenciar entre las dos márgenes del Guadiana. Es más abundante en la región alentejana $\mathrm{y}$, asimismo, parece difundirse de forma distinta. Desde Porto Torrão, se difunde de forma radial hacia varias categorías de poblados. Estas cerámicas debieron proceder de la Estremadura portuguesa y llegar mediante el curso del Sado al asentamiento central de Porto Torrão. Desde ahí se difunde como se ha comentado. En cambio, en la margen izquierda son más escasas y aparecen prácticamente sólo en poblados de primer orden. El grupo Inciso aparece indistintamente en todos las categorías de asentamientos, aunque en los poblados de tercer orden se reduce normalmente a uno o pocos ejemplares.

Las diferencias entre las regiones de a uno y otro lado del río no se limitan a una distribución asimétrica del Puntillado Geométrico. Como habíamos mencionado anteriormente, ambas regiones son diferentes en la distribución y en la representación de ídolos (Hurtado e.p.). También veíamos en el apartado 4.2.1 que tanto las estructuras del enterramiento campaniforme como los tipos de recipientes asociados son distintas en uno y otro lado. En la margen derecha todos se realizan en las estructuras dolménicas, que predominan en la región desde épocas anteriores. Normalmente se le asocian cazuelas campaniformes. En cambio en la margen izquierda, aunque no se produce una fuerte ruptura en época campaniforme como es la introducción del enterramiento individual tan común en muchas otras regiones geográficas, sí parece producirse una ligera evolución a enterramientos colectivos pero en estructuras menores. Todos los contextos de enterramientos campaniformes en esta área se producen en tholos o estructuras circulares, y se percibe una individualización de los ajuares. El tipo de recipiente predominante según el registro son los cuencos campaniformes. 
Todos estos factores, que se suman a los estudios de territorio que se vienen produciendo desde hace aproximadamente una quincena de años (Hurtado 1986; 1995; 1999; 2000), sugieren la existencia de un territorio posiblemente definido en la margen izquierda de la CMG. En cambio, en la margen derecha estos marcos territoriales no están muy claros. No sabemos si el poblamiento de toda la región alentejana se vertebraba en torno al asentamiento de Porto Torrão conformando así un único territorio, o si por el contrario existían varios marcos de organización política. Hay que mencionar algunos estudios que han planteado diversos territorios de dimensiones menores o situaciones de agregación similares en esa región, por ejemplo en Serra d'Ossa (Calado 2001) y en la Ribera del Álamo en torno a Perdigões (Valera 2006). No obstante, hay que apuntar que sólo en los asentamientos de La Pijotilla y, por otro lado, de Porto Torrão se encuentran cerámicas cordadas, y que es en estos dos sitios donde se tienen las fechas más altas relacionadas con el Marítimo. Sean cuales fueran los marcos de organización de la margen derecha, parece que el asentamiento de Porto Torrão (al igual que su homólogo de La Pijotilla) se erige como el primer emplazamiento principal de la región, y no sólo desde los inicios del fenómeno campaniforme sino desde época anterior según las evidencias estratigráficas. Estos territorios están conformados por tanto previamente al Calcolítico Final, desde la fase de La Pijotilla de Hurtado pero retrotrayendo las fechas prácticamente a inicios del III Milenio a.C. En ambos yacimientos principales se encuentran niveles estratigráficos correspondientes con fases previas al Campaniforme. La irrupción de este fenómeno se produce pues una vez establecidos estos territorios, y sus pautas jerárquicas quedan materializadas en la distribución de las cerámicas impresas. Sin embargo en un momento más tardío, representado por las cerámicas incisas, se perciben cambios notables en las pautas de distribución de estos bienes de prestigio y, por tanto, en las formas de promoción y en las relaciones jerárquicas de estos territorios. El grupo Inciso muestra una dispersión mayor en términos cuantitativo y espacial. Este florecimiento no debe entenderse en cambio como una "democratización" de este material hacia otros sectores sociales. El análisis semi-micro de los contextos disponibles evidencia unos patrones similares a los anteriores, en el sentido de que estas cerámicas siguen apareciendo en el centro neurálgico de los emplazamientos, asociados a otros ítems preciados. La diferencia fundamental radica en el frecuente hallazgo de estas cerámicas en asentamientos de segundo y tercer orden distribuidos básicamente en la semiperiferia (en torno a los enclaves principales) y también, aunque en menor número, en la periferia de los territorios. No obstante, no hay que olvidar que esta distribución sigue siendo selectiva, porque no a todos los asentamientos del momento llegan cerámicas incisas. De hecho, en diversas zonas se difunde por algunos yacimientos y en cambio no por otros que están a medio camino. ¿Qué podemos entrever de esta situación?

El registro arqueológico muestra unas distribuciones de estos materiales que no se deben a razones de mercado, de gustos, etc. Muestran pautas claramente restrictivas en el acceso a estos materiales que pudieron deberse más bien a factores y estrategias políticas. El uso de estos materiales indistintamente por todos los individuos de un sector pudiente económicamente plasmaría unas distribuciones más regulares y homogéneas a lo largo de toda el área estudiada. Creemos más factible relacionar estos objetos con un sector social reducido no sólo con base en criterios económicos sino además y fundamentalmente políticos; en definitiva, el sector dirigente político-¿religioso? ¿Cómo si no podríamos comprender unos patrones de promoción y de difusión tan selectivos y heterogéneos? Desde esta perspectiva, la notable diferencia que muestra la distribución de las cerámicas incisas respecto a las impresas debe ponerse en relación con cambios en las formas de relación entre los asentamientos $\mathrm{y}$, por tanto, con modificaciones de las estrategias políticas. Creemos que básicamente se debe a un proceso de fragmentación de los territorios anteriormente establecidos, un momento de relativa disgregación seguramente inmerso en un ambiente más hostil y bélico, donde el sector dirigente de esos territorios promueve estrategias de redefinición de los marcos políticos. En este sentido, no sorprende el aumento de armas (puñales y toda una serie de objetos metálicos asociados al campaniforme tardío) y fortificaciones que parece producirse en ese momento. Las acciones políticas y de defensa encaminadas a la remodificación territorial se plasmarían en buena medida sobre los asentamientos de la semiperiferia y periferia, donde las fricciones territoriales son más evidentes debido a la proximidad y contacto con grupos humanos de marcos políticos distintos. Por esta razón el rango de dispersión del grupo Inciso es más extenso. En este punto, merece la pena recordar la distribución del inciso con impresiones toscas, fundamentalmente sobre el propio curso del río pero en ambas márgenes. No sabemos si responde a una dispersión indiferente en ambos territorios o si por el contrario refleja algunas modificaciones fronterizas de los espacios anteriores. Por ejemplo, la propuesta de A.C. Valera sobre el territorio de la Ribera del Álamo en torno a Perdigões supone unas fronteras dinámicas que en ocasiones 
se hubieran extendido incluso hacia la margen izquierda del Guadiana (2006: 188 y ss.).

En el proceso de atomización y colapso de los territorios, aunque se puede pensar en procesos de emulación por parte de las élites locales, hay que contar con ciertas objeciones. La dispersión periférica del inciso es superior comparada con aquella de las cerámicas impresas, pero es francamente escasa en términos globales. Si la reproducción de estos objetos hubiese podido realizarse fácilmente mediante emulación por parte de élites locales para mantener o acrecentar sus posiciones, la evidencia arqueológica sería quizás distinta. Tampoco la comparación entre las calidades de los recipientes del centro y de la periferia parece reveladora, pues contenedores de menor calidad aparecen en ambas zonas. Aunque no se pueden descartar procesos de emulación, es factible pensar en otros tipos de procesos relacionados con estrategias políticas diseñadas desde los asentamientos principales para mantener la unidad territorial en un momento presuntamente bélico y disgregador.

Según las características del poblamiento y de los marcos políticos que estamos analizando, e intentando profundizar en las relaciones y dependencias entre los asentamientos y territorios, se propone un modelo básico que engloba 4 niveles de alcance o escala.

- Escala 1 (transregional): se refiere a los contactos a larga distancia o largo alcance, generalmente relacionando los que hemos denominado poblados de $1^{\mathrm{o}}$ orden (¿puntualmente también de $2^{\circ}$ orden?) con otros poblados importantes de territorios bastante lejanos. Esta se correspondería con la presencia de materiales peculiares sólo en poblados principales, y que se relacionan con focos lejanos: campaniforme cordado, que seguramente procede del norte europeo, en Pijotilla y Porto Torrão; pastillas repujadas en Pijotilla y escasos yacimientos de $2^{\circ}$ orden, seguramente mediante contactos con el Sudeste francés (Hurtado y Amores 1982). Parece tratarse de relaciones bilaterales como demuestra este último caso de las pastillas repujadas en La Pijotilla y la documentación de un ídolo característico de esta región en el Sudeste francés (Hurtado, e.p.).

- Escala 2 (interterritorial): entre poblados de $1^{\mathrm{o}}$ orden (¿puntualmente también de $2^{\circ}$ orden?) de territorios adyacentes o próximos. Esta se correspondería con la distribución de cerámicas campaniformes de tipo Puntillado Geométrico o Marítimo fundamentalmente en poblados de este tipo. Particularmente, es muy interesante que la presencia de Puntillado Geométrico en la margen izquierda del Guadiana Medio se limite a poblados de este tipo. También se trataría de relaciones bilaterales.
— Escala 3 (intraregional alto): entre los poblados de $1^{\circ}$ orden de un territorio y el resto del grupo. Puede explicar las características homogéneas y en algunos casos propias de algunas zonas. Podría corresponderse con la distribución unilateral del Puntillado Geométrico de Porto Torrão y de algunos de los poblados que conforman su unidad territorial. Posiblemente, la variabilidad propia que presentan los motivos decorativos que rellenan rombos y triángulos en este territorio se relacionase con esta escala. Por último, parece que la distribución de los distintos estilos de ídolos en el Suroeste peninsular (Hurtado e.p.) responde a redes de este alcance, dada la estrecha vinculación de cada variedad estilística con posibles unidades territoriales. En lo que respecta exclusivamente a la cerámica campaniforme, comprende fundamentalmente relaciones de tipo unilaterales, desde los poblados principales a los menores.

- Escala 4 (intraregional bajo): Se refiere a las relaciones de bajo alcance que ocurren entre cualquier tipo de poblados dentro de un territorio (asentamientos de $2^{\circ}$ y $3^{\circ}$ orden). Seguramente, se corresponde con la transferencia de materias y productos básicos. Las cerámicas campaniformes estuvieron totalmente negadas a esta escala de relaciones, al menos con seguridad en la primera fase de este fenómeno.

El modelo de organización y relaciones territoriales planteado contemplaría difusiones unilaterales y bilaterales. La mayoría de los niveles o escalas comprendería fundamentalmente relaciones bilaterales. En cambio, la Escala 3 -intraregional-parece reflejar una promoción del campaniforme desde poblados superiores a otros de menor importancia, básicamente unilateral. Así lo indican entre otros argumentos las fechas radiocarbónicas disponibles. No obstante, no descarta movimientos en sentido contrario, o incluso simétricos, pues se conocen otros tipos de materiales que se transfieren en redes de estas clases. Según los escasos análisis arqueométricos efectuados hasta el momento a nivel general, la mayoría de cerámicas campaniformes parecen producirse con arcillas propias de cada sitio o región (Salanova 2005: 9). Ahora bien, puede que la mayoría de ejemplares analizados procedan de los poblados principales, lo que impide una comparación imparcial entre categorías de asentamientos y, por tanto, testar apropiadamente las propuestas sobre las formas de difusión de estas cerámicas a lo largo del territorio. Por ejemplo, debemos anotar el caso de Fraga da Pena que aunque no se sitúa en nuestro marco de estudio sí se encuentra en la región colindante del centro portugués, concretamente en la cuenca del río Montego en la zona de 
Fornos de Algodres. No parece tratarse en absoluto de un asentamiento relevante en cuanto a la organización del territorio se refiere, y justo por ello nos interesa comentar que se han encontrado allí 7 recipientes importados de otros asentamientos, según indican los análisis arqueométricos, de los cuales 5 son campaniformes (Dias, Valera y Prudencio 2005: 47). Además, en última instancia, el presunto carácter local de estas producciones no descarta realmente la implicación directa o indirecta de algún elemento foráneo, máxime tratándose de unas cerámicas con un rol importante en ceremonias ritualizadas y actos de sociabilidad a niveles intra-asentamiento e inter-asentamiento.

A la espera de nuevos análisis de cerámicas en los asentamientos de segunda y tercera categoría, podría ser útil distinguir entre los términos difusión y promoción del campaniforme. Dado el handicap de la disparidad comparativa en los análisis efectuados, no podemos asegurar si estas cerámicas se elaboran normalmente en cada emplazamiento o si muchas de ellas proceden de fuera. ¿Pero es realmente el sitio donde se fabrican estas piezas lo más importante para comprender el significado de este fenómeno? Se elaboren en cada uno de los sitios o no, lo que parece claro es que la promoción (no sabemos si la difusión) de este material procede fundamentalmente de los poblados principales. El sector dirigente que tutela esta vajilla lujosa en los poblados principales controló su promoción hacia asentamientos concretos mediante, sospechamos, estrategias políticas. Esta perspectiva podría contemplar incluso la elaboración de las cerámicas en los sitios receptores de segundo y tercer orden $-\mathrm{y}$ por tanto con arcillas locales- aunque con un componente humano y tecnológico venido de fuera, de otro asentamiento. No debemos olvidar, que estas preciadas cerámicas pueden haber servido como contenedores en ceremonias ritualizadas y congregaciones de gente encaminadas hacia la creación y el mantenimiento de clientelas sociales (Sherratt 1987; 1991; Garrido 1995; Garrido 2005).

Siguiendo en parte esta interpretación, creemos que la dispersión del campaniforme a lo largo de la CMG se relacionó con estrategias políticas destinadas al mantenimiento y a la creación de pactos, convenios y alianzas entre asentamientos y territorios. Si este era el objetivo fundamental de estas reuniones ritualizadas, el sitio donde se produjesen no es de tan suma importancia. No obstante, dentro de un mismo territorio parece que la promoción se realizó desde poblados principales a otros menores. Esto nos lleva a plantear que podrían haberse producido movimientos de pequeños sectores de población que, a modo de "comitivas", hubieran buscado fraguar pactos y convenios con otros asentamientos dispuestos en la semiperiferia y periferia de los territorios (como bien indica la distribución del Inciso), allá donde la fricciones territoriales se harían evidentes. Estos grupos selectos no estarían conformados sólo por los agentes efectivos a nivel político o guerrero, sino por toda una serie de representantes de otras esferas culturales o económicas de la sociedad como chamanes, alfareros, herreros $\mathrm{y}$, además, súbditos puestos a cualquier tipo de servicio. Existen evidencias de movilizaciones de gente prehistórica a veces incluso a largas distancias (Price y otros 2004; Spindler 1993; Fitzpatrik 2003; citados en Thomas 2005) y vienen siendo más comunes hoy en día debido a la aplicación de nuevas técnicas de identificación.

La vajilla campaniforme constituía un símbolo inequívoco, con un significado y mensaje concreto que conseguiría una identidad grupal de todos los individuos que tomaban partido en las ceremonias. Pero al mismo tiempo era el contenedor de alguna sustancia de gran relevancia, posiblemente algún tipo de bebida alcohólica u otras sustancias que a modo de «lubricantes sociales» facilitarían la consecución de dichos pactos (Sherratt 1987: 82 y 91) y, por tanto, la consolidación en las relaciones entre las partes integrantes.

No se excluyen en absoluto otro tipo de conductas dirigidas a estos mismos fines, como la consecución de matrimonios entre miembros de los sectores dirigentes de distintos asentamientos o territorios, etc.

Este tipo de clientelas políticas entre asentamientos permite además el reclutamiento de soldados y la disposición de un número mayor de efectivos humanos para contiendas militares (Sherrat 1987; 1991), en un momento bélico evidenciado no sólo por la fragmentación de territorios planteada, sino por el aumento de armas, fortificaciones y, también, por el presunto descenso demográfico que parece reflejar este momento de transición a la Edad del Bronce.

Sabemos que la práctica y generalización de muchas conductas culturales, sea o no bajo el empleo de materiales muebles, se produce en numerosas ocasiones por razones o patrones ideológicos que poco tienen que ver con el efecto social que éstas suponen. Por ejemplo, las creencias religiosas llevan a generalizar a toda una comunidad determinados tipos de conducta que tienen a medio y largo plazo un efecto importante en la propia formación social, desconocido en la mayoría de los casos por la mayor parte de la sociedad. De esta forma, y mediante la ignorancia de la mayoría de individuos de una comunidad cualquiera, las religiones reproducen las desigualdades y clases sociales, aunque en muchos casos también aportan beneficios a todo el grupo (Escacena y García Rivero, e.p.). ¿Qué consideración merece esto en el caso del campaniforme? 
Evidentemente, no podemos saber hasta qué punto el sector de población dirigente fue consciente de los efectos secundarios que, en el plano social, la cerámica campaniforme promocionaba y reproducía. Es probable que el uso de este material estuviera tan inmerso en una esfera ritual que no hubiera tenido lugar ningún tipo de intencionalidad o manipulación política. El misterio que hubiera existido en torno a la sacralidad del fenómeno quizás hubiera priorizado y divulgado aspectos diversos, por ejemplo, de veneración de los antepasados, de identidad genealógica (Thomas 2005: 117), otros de naturaleza más mitológica -como la caza de monstruos del mundo espiritual-(Case 2004: 29), etc. Pero con intencionalidad o sin ella, estas conductas arrastran frecuentemente consecuencias sobre parte de la sociedad o sobre toda ella que, al margen de clasificarlas desacertadamente como buenas o malas, son importantes para el propio desarrollo social de la comunidad. En este sentido, merece la pena recordar a K. Kristiansen cuando se refiere al ritual, a la guerra y a los intercambios como mecanismos básicos a través de los cuales funcionan las estrategias socioeconómicas, y cuando lo hace aún de forma más concreta respecto a la sacralidad del ritual como un mecanismo que, vinculado al rango social (superioridad social de alguna de las partes), es capaz de crear relaciones entre centro y periferia, más allá del marco local (Kristiansen 2001: 89-95).

Lejos de pretender siquiera entrar en asuntos de esta magnitud, lo que sí puede establecerse es una serie de "efectos sociales" que, según las circunstancias, serían acrecentados por el repertorio campaniforme. El primer efecto es el prestigio individual. El segundo es la pertenencia a un grupo reducido y privilegiado dentro de un asentamiento cualquiera. Un tercer efecto está relacionado con la pertenencia a un grupo pero a nivel territorial (interasentamientos). Es decir, la pertenencia a grupos distintos económica y socialmente que buscan la unión entre sí y, por otro lado, se distancian del resto de la comunidad. A. Hernando se ha referido a este efecto y a la comunión entre grupos dirigentes o grupos paralelos de poder como el surgimiento de una «identidad estamental» (Hernando 2002: 160-161). Es razonable pensar que hubieran existido conductas exclusivas de grupos de este tipo. Podrían haberse basado, por ejemplo, sobre conceptos o valores ideológicos, de identidad y pertenencia a un grupo elegido, como por ejemplo el ideal y el honor guerrero. Quizás, la intención de estas conductas por parte de los jefes y clanes de cada asentamiento fuera la estabilidad y el propio mantenimiento en el poder. No obstante, esto facilitaría también la creación de pactos y alianzas entre asentamientos en el proceso de remodificación de territorios anteriormente propuesto.
No existe aún un número suficiente de fechas absolutas como para concretar lo deseado en algunos aspectos. No obstante, aquellas de las que disponemos indican que el fenómeno campaniforme irrumpe en la región mucho antes de lo que se pensaba apenas hace una década. Las fechas más altas proceden de los emplazamientos de Porto Torrão y de La Pijotilla. Indican que las cerámicas puntilladas - de tipos Marítimo y Puntillado Geométrico- llegan a estos dos enclaves (y por tanto a la región) a finales del primer cuarto o a principios del segundo cuarto del III Milenio a.C ${ }^{6}$. El sitio de San Blas arroja la fecha de mitad del III Milenio a.C., mientras que Porto das Carretas ofrece otra datación ya en el tercer cuarto del mismo milenio. Las mismas fechas de Porto Torrão, La Pijotilla y San Blas son las existentes para datar el grupo inciso, si bien los estratos de donde proceden las piezas se sitúan estratigráficamente en un post quem respecto a los niveles datados. San Blas y Escoural presentan una fechas algo posteriores, alrededor del 2300 a.C. y 2500 a.C., respectivamente. La fecha más reciente corresponde a $\mathrm{Pa}-$ lacio Quemado, alrededor del 1620 a.C., pero como apuntan sus propios arqueólogos conviene dejarla en reserva (Hurtado y Enriquez 1991: 87).

En definitiva, podría proponerse para el campaniforme de la región un marco cronológico desde el segundo cuarto hasta finales del III Milenio a.C., aproximadamente.

A la espera de nuevas intervenciones y estudios arqueológicos, y de que se realicen fechas absolutas principalmente para los asentamientos secundarios situados lejos de los principales, estaríamos hablando del campaniforme en la CMG como un fenómeno continuo pero, quizás, con una dinámica en el ritmo de cambio -político y social- más rápida que en épocas anteriores. Así, incluso podría hablarse de ciertas diferencias en el contexto y estrategias políticas entre el inicio y los últimos momentos del fenómeno campaniforme. Probablemente existiesen también diferencias en el propio sistema económico. Algunos asentamientos muestran, en la etapa campaniforme, cambios en las proporciones de los restos de fauna, y por tanto, en la dieta. Se trata de un aumento de especies salvajes -como el ciervo y el jabalí- en detrimento de algunas especies domésticas comunes hasta ese momento - cabras, cerdos, etc.-Así se ha constatado en asentamientos como Monte da Tumba (Antunes 1987) y Porto Torrão (Arnaud 1993). Pero por momento, más por falta de estudios de este tipo que por otra cosa, esto no puede en absoluto hacerse extensible para toda la región.

6. Tanto en esta como en las siguientes nos referimos a fechas calibradas. 
No hay duda alguna, según el panorama actual de la investigación, de que poco tiene que ver el sistema general del Calcolítico donde penetra el fenómeno campaniforme con aquel otro existente en el Bronce Antiguo. En contraposición con la idea generalizada de un proceso en desarrollo hacia la centralización y el establecimiento del poder como un todo homogéneo, se percibe más bien una tendencia hacia la fragmentación. Un proceso que evoluciona hacia una cierta individualización tanto de la escala de poder como de la población, incluso en ámbitos culturales y modelos de comportamiento. No sorprende esta fragmentación de los esquemas sociales anteriores, implantados desde milenios atrás, y apoyados en un sistema económico fundamentalmente agrícola, al que se dedicaba la mayoría de la población. Una vez surgen nuevos sectores de producción y se desarrollan notablemente otros ámbitos, como por ejemplo la metalurgia, un proceso de resquebrajamiento ideológico, político, social y cultural es evidente. Fundamentalmente aquí reposa la importancia del fenómeno campaniforme en el Suroeste de la Península Ibérica.

\section{BIBLIOGRAFÍA}

ALDAY RUIZ, A. (2001): "Vías de intercambio y promoción del campaniforme marítimo y mixto sobre el interior peninsular", Cuadernos de Arqueología de la Universidad de Navarra 9: 111-174.

ALMAGRO, M. (1959): "Excavaciones en el sepulcro de corredor megalítico de Lácara, Mérida (Badajoz)", Revista de Estudios Extremeños XV, II: 249-314

ANTUNES, M.T. (1987): “O povoado fortificado calcolítico do Monte da Tumba. IV- Mamíferos (nota preliminar)", Setúbal Arqueológica 8: 103-144.

ARNAUD, J.M. (1993): “O povoado calcolítico de Porto Torrão (Ferreira do Alentejo): síntese das investigações realizadas", Vipasca 2: 41-60.

BOAST, R. (1995): "Fine pots, pure pots, Beaker pots", en I. Kinnes y G. Varndell (Eds.): Unbaked urns of rudely shape (Essays on British and Irish pottery for Ian Longworth). Oxford: Oxbow books.

BOAVENTURA, R. (2000): "O campaniforme do habitat do Pombal (Monforte, Alto Alentejo, Portugal)", Actas do $3^{\circ}$ Congresso de Arqueologia Peninsular, vol IV. Pré-Historia Recente da Península Ibérica: 291-304. Porto: Adecap.

BONSOR, G. (1899): Les colonies agrícoles pre-romaines de la Vallée du Betis, Revue Archéologique XXXV. Paris.
BOSCH-GIMPERA, P. (1940): "The types and chronology of Western European beakers", Man: 6-10.

BRODIE, N. (1997): "New perspectives on the bellbeaker culture", Oxford Journal of Archaeology 16 (3): 297-314.

- (1998): "British bell beakers: Twenty-five years of theory and practice", en M. Benz y S. van Willigen (eds.), Some new approaches to the Bell Beaker phenomenon. Lost paradise...? Proceedings of the $2^{\text {nd }}$ meeting of the "Association Archéologie et gobelets”, Feldberg (Germany), Abril 1997, BAR, Series Internacionales, 690: 43-56.

- (2001): "Technological frontiers and the emergence of the Beaker culture", en F. Nicolis (ed.), Bell beakers today. Pottery, people, culture, symbols in prehistoric Europe, volume II: 487-496, Proceedings of the International Colloquium Riva del Garda (Trento, Italy), 11-16 May 1998.

BUBNER, T. (1979): “Ocupação campaniforme do Outeiro de São Bernardo”, Ethnos 8: 139-151. Lisboa.

BURGESS, C. y SHENNAN, S. (1976): "The beaker phenomenon: some suggestions", en C. Burgess y R. Miket (eds.), Settlement and economy in the Third and Second Millenia B.C. British Archaeological Reports 33. Oxford.

CALADO, M. (1993): Carta arqueológica do Alandroal. Alandroal: Câmara Municipal de Alandroal.

- (2001): Da Serra d'Ossa ao Guadiana. Um estudo de pré-história regional, Trabalhos de Arqueologia 19. Lisboa: Instituto Português de Arqueologia.

CARDOSO, J.L. (2001): "Le phénomene campaniformes dans les basses vallées du Tage et du Sado (Portugal)", en F. Nicolis (ed.), Bell beakers today. Pottery, people, culture, symbols in prehistoric Europe, volume II: 139-154. Proceedings of the International Colloquium Riva del Garda (Trento, Italy), 11-16 May 1998.

CARDOSO, J.L y NORTON, J. (2004): “As caçoilas campaniformes da anta de Bencafede (Évora)", Revista Portuguesa de Arqueología 7 (nº1): 129-136.

CARTAILHAC, E. (1886): Les Âges Préhistoriques de l'Espagne et du Portugal. Paris: Reinwald.

CASE, H. (1995): "Beakers: loosening a stereotype", en I. Kinnes and G. Varndell (eds.), Unbaked urns of rudely shape. Essays on british and irish pottery: 55-67, Oxford: Oxbow books.

- (2004): Beakers and the beaker culture, en J. Czebreszuk (ed.), Similar but different: Bell beakers in Europe: 11-34, Poznan: Adam Mickiewicz University.

CASTILlO, A. del (1922): "La cerámica incisa de la cultura de las cuevas de la Península Ibérica y el problema del origen de la especie del vaso 
campaniforme", Anuario de la Universidad de Barcelona: 1-20. Barcelona.

- (1928): La cultura del vaso campaniforme. Su origen y extensión en Europa. Barcelona: Universidad del Barcelona.

- (1943): "Cronología de la cultura del vaso campaniforme en la Península Ibérica”, Archivo Español de Arqueología XVI: 388-435. Madrid.

- (1944): "Cronología de la cultura del vaso campaniforme en Europa", Archivo Español de Arqueología XVII: 1-67. Madrid.

CHAPMAN, R.W. (1987): "Once upon a time in the West: some observations on beaker studies", en W. H. Waldren and R. C. Kennard (eds.), Bell beakers of the Western Mediterranean. Definition, interpretation, theory and new site data. British Archaeological Reports, International Series, 331 (i): 61-79, Oxford.

CHILDE, V.G. (1947): The dawn of European civilization. London: Kegan Paul, Trench, Trubner and co., Ltd.

- (1958): The Prehistory of European society. London: Penguin Books.

CLARKE, D.L. (1976): “The Beaker network. Social and economic models", en J.N. Lanting y J.D. Van der Waals (eds.), Glockenbecher Symposium (Oberried, 1974): 459-476. Fibula-van Dishoek, Bussum-Haarlen.

DIAS, M.I.; VALERA, A.C. y PRUDENCIO, M.I. (2005): "Pottery production technology throughout the third millennium $\mathrm{BC}$ on a local settlement network in Fornos de Algodres, central Portugal", en M. I. Prudêncio, M.I. Dias y I.J.C. Waerenborgh (eds.), Understanding people through their pottery. Proceedings of the $7^{\text {th }}$ European Meeting on Ancient Ceramics (Octuber 27-31, 2003): 41-50. Lisboa, Instituto Tecnológico e Nuclear.

ENRÍQUEZ NAVASCUÉS, J.J. (1989): Los poblados calcolíticos de la Cuenca Media del Guadiana. Aproximación al estudio de los comprendidos entre las Vegas Altas y Bajas del Guadiana (La comarca de Mérida). Madrid: Universidad Complutense (colección Tesis Doctorales).

- (1990): El Calcolítico o Edad del Cobre de la Cuenca Extremeña del Guadiana: Los poblados. Badajoz: Museo Arqueológico Provincial.

ENRÍQUEZ, J.J. y IÑESTA, J. (1985): "Notas sobre los poblados calcolíticos de la comarca de Llerena (Badajoz)", Estudios de Arqueología Extremeña (Homenaje a Cánovas Pesini): 15-24. Badajoz: Diputación de Badajoz.

ESCACENA, J.L. y GARCÍA RIVERO (e.p.): "Interdemic selection and phoenician priesthood.
Darwinians reflections on the archaeoastronomy of Southern Spain", en H.J. Muscio y G.E. López (eds.), Theoretical and Methodological issues in Evolutionary Archaeology: Toward a unified Darwinian Paradigm.

FARINHA DOS SANTOS, M.; SOARES, J. y TAVARES DA SILVA, C. (1972): "Campaniforme da Barrada do Grilo", O Arqueologo Portugués, Série III, vol. VI: 163-192.

GALLAY, A. (1988): « Le phénomène campaniforme: L'heure des remises en question ", Actes des Rencontres Néolithiques de Rhône-Alpes (Lyon) 5 : 6-14.

- (1998): “L'énigme campaniforme", Archéologia, Hors-série, 9 (Dec. 97-Jan. 98): 14-19.

GARRIDO PENA, R. (1995): "El campaniforme en la Meseta Sur: nuevos datos y propuestas teóricas", Complutum 6: 123-151.

- (1997): "Bell beakers in the Southern Meseta of the Iberian Peninsula: socioeconomic context and new data", Oxford Journal of Archaeology 16 (2): 187-209.

- (2001): "La Prehistoria: ¿ciencia del pasado remoto o discurso ideológico contemporáneo?", Tiempo y Tierra (Revista de la Asociación Española del profesorado de Historia y Geografía) 12: 25-44. Madrid.

- (2005): "El laberinto campaniforme: Breve historia de un reto intelectual", en M.A. Rojo, R. Garrido y I. García (coords.): El campaniforme en la Península Ibérica y su contexto europeo: 29-44. Valladolid: Universidad de Valladolid.

GARRIDO PENA, R. y MUÑOZ LÓPEZ-ASTILLEROS, K. (2000): "Visiones sagradas para los líderes. Cerámicas campaniformes con decoración simbólica en la Península Ibérica”, Complutum 11: 285-300.

GOMES, M.V. (1991): “Corniformes e figuras asociadas de dois santuários rupestres do Sul de Portugal. Cronologia e interpretação", Almansor, Montemoro-Novo, 9: 17-74.

GONÇALVES, V. y CATARINA SOUSA, A. (2000): “O grupo megalítico de Reguengos de Monsaraz e a evolução do megalitismo no Occidente peninsular (espaços de vida, espaços da morte: sobre as antigas sociedades camponesas em Reguengos de Monsaraz)", en V.S. Gonçalves (ed.), Muitas antas, pouca gente? Actas do I Colóquio Internacional sobre Megalitismo: 11-104.

HARRISON, R.J. (1977): The bell beakers cultures of Spain and Portugal, Cambridge-Massachusetts: Peabody museum of archaeology and ethonology, Harvard University.

- (1977b): "Beaker cultures of Iberian, France and West Mediterranean Islands. 2.200-1.500 b.c.", $B A R$, Supplementary Series 26: 5-26. Oxford. 
- (1980): The Beaker Folk. Cooper Age Archaeology in Western Europe, London: Thames \& Hudson.

HERNANDO. A. (2002): Arqueología de la identidad. Madrid: Akal.

HURTADO, V. (1984): El yacimiento de 'La Pijotilla' (Badajoz). Estudio de relaciones culturales. Tesis doctoral inédita.

- (1985): "Excavación de una sepultura circular de la Edad del Bronce en Guadajira", Estudios de Arqueología Extremeña (Homenaje a Cánovas Pesini): 25-36. Badajoz: Diputación Provincial de Badajoz.

- (1986): "El Calcolítico en la Cuenca Media del Guadiana y la necrópolis de La Pijotilla", Actas de la Mesa Redonda sobre Megalitismo peninsular (Madrid 1984): 51-75. Madrid.

- (1991): "Informe de las excavaciones de urgencia en "La Pijotilla". Campaña de 1990”, Extremadura Arqueológica, II. "I Jornadas de Prehistoria y Arqueología en Extremadura (1986-1990)": 45-67. Mérida-Cáceres.

- (1995): “Interpretación sobre la dinámica cultural en la Cuenca Media del Guadiana (IV-II Milenio A.N.E.)", Extremadura Arqueológica V. Homenaje a la Dra. D ${ }^{a}$ Milagro Gil-Mascarell Boscà: 53-80: 53-80.

- (1999): "Los inicios de la complejización social y el campaniforme en Extremadura", Spal 8: 49-83. http://dx.doi.org/10.12795/spal.1999.i8.04

- (2000): "El proceso de transición a la Edad del Bronce en la Cuenca Media del Guadiana. Ruptura o continuidad", Actas do $3{ }^{\circ}$ Congresso de Arqueologia Peninsular, vol IV. Pré-Historia Recente da Península Ibérica: 381-398. Porto: ADECAP.

- (2004): "El asentamiento fortificado de San Blas (Cheles, Badajoz). III Milenio A.C.", Trabajos de Prehistoria 61 (1): 141-155.

- (2005): "El campaniformes en Extremadura. Valoración del proceso de cambio socioeconómico en las cuencas medias del Tajo y Guadiana”, en M.A. Rojo, R. Garrido y I. García (coordc.): El campaniforme en la Península Ibérica y su contexto europeo: 321-335. Valladolid: Universidad de Valladolid.

- (e.p.): "Ídolos, estilos y territorios de los primeros campesinos en el sur peninsular", Trabajos de Prehistoria (formato web).

HURTADO, V. y AMORES, F. (1982): "Relaciones culturales entre el Sudeste francés y La Pijotilla (Badajoz) en el Calcolítico: las pastillas repujadas y el campaniforme cordado", Habis 13: 189-209.

HURTADO, V. y ENRÍQUEZ, J.J. (1991): “Excavaciones en Palacio Quemado (Alange, Badajoz).
Informe preliminar", I Jornadas de Prehistoria y Arqueología en Extremadura (1986-1990). Extremadura Arqueológica II: 69-88.

HURTADO, V. y GARCÍA SANJUÁN, L. (1994): “La necrópolis de Guadajira (Badajoz) y la transición a la Edad del Bronce en la Cuenca Media del Guadiana”, Spal 3: 95-144. http://dx.doi.org/10.12795/ spal.1994.i3.05

HURTADO, V.; MONDÉJAR. P. y PECERO, J.C. (2000): "Excavaciones en la Tumba 3 de La Pijotilla", Extremadura Arqueológica VIII. El Megalitismo en Extremadura (Homenaje a Elías Diéguez Luengo): 249-266. Mérida.

JUÁREZ SÁNCHEZ-RUBIO, C. (1979): Caracteres climáticos de la cuenca del Guadiana y sus repercusiones agrarias. Salamanca: Universidad de Salamanca.

KALB, P. y HÖCK, M. (1997): “O povoado fortificado, calcolítico do Monte da Ponte, Évora”, II Congreso de Arqueología Peninsular, Tomo II: Neolítico, Calcolítico y Bronce: 417-423. Zamora: Fundación Rei Afonso Henriques.

KRISTIANSEN, K. (2001): Europa antes de la Historia. Los fundamentos prehistóricos de la Europa de la Edad del Bronce y la primera Edad del Hierro. Barcelona: Ediciones Península.

KUNST, M. (2001): "Invasion? Fashion? Social rank? Consideration concerning the bell beaker phenomenon in Copper Age fortifications of the Iberian peninsula", en F. Nicolis (ed.), Bell beakers today. Pottery, people, culture, symbols in prehistoric Europe, volume I: 81-80, Proceedings of the International Colloquium Riva del Garda (Trento, Italy), 11-16 May 1998.

- (2005): "El campaniforme en Portugal. Breve resumen", en M.A. Rojo, R. Garrido y I. García (coords.): El campaniforme en la Península Ibérica y su contexto europeo: 197-211. Valladolid: Universidad de Valladolid.

LAGO, M.; DUARTE, C.; VALERA, A.; ALBERGARIA, J.; ALMEIDA, F. y FAUSTINO, A. (1998): "Povoado dos Perdigões (Reguengos de Monsaraz): dados preliminares dos trabalhos arqueológicos realizados em 1997", Revista Portuguesa de Arqueología 1 (1): 45-152.

LANTING, J.N. y WAALS, J.D. van der (1976): "Beaker culture relations in the Lower Rhine Basin", Glockenbecher Symposium (Oberried, März 1974): 1-80.

LAZARICH GONZALEZ, M.(1999): El Campaniforme en Andalucía Occidental. Cádiz: Universidad de Cádiz. 
LEISNER, G. y LEISNER, V. (1955): Antas nas Herdades da Casa da Bragança no Concelho de Estremoz, Lisboa: Fundaçao da Casa de Bragança.

- (1959): Die Megalithgräber der Iberischen Halbinsel, Der Wester. Berlín : Walter de Gruyter \& Co.

LEISNER, V. (1965): Die Megalithgräber der Iberischen Halbinsel : Der Westen. Berlín: Gruyter.

LEITÃO, M.; NORTH, C.T.; NORTON, J.; VEIGA FERREIRA, O. y ZBYSZEWSKI, G. (1978): “La céramique de la culture du vase campaniformes du Portugal- Essai de systématisation", Com. Ser. Geol. de Portugal 63: 449-520.

MONGE SOARES, A. (1992): "O povoado calcolítico dos Três Moinhos (Baleizão, concelho de Beja)", Setúbal Arqueológica, volumen IX-X: 291-314.

MONGE, A.M.; ARAÚJO, M.F. y PEIXOTO, J.M. (1994): "Vestígios da práctica de metalurgia em povoados calcolíticos da Bacia do Guadiana, entre Ardila e o Chanca", en J.M. Campos, J.A. Pérez y F. Gómez (eds.), Arqueología en el entorno del Bajo Guadiana: 165-200. Sevilla: Junta de Andalucía y Universidad de Huelva.

MÜLLER, J. y van WILLIGEN, S. (2001): "New radiocarbon evidence for european Bell Beakers and the consequences for the diffusion of the Bell Beaker phenomenon", en F. Nicolis (ed.), Bell Beakers today. Pottery, people, culture, symbols in prehistoric Europe, volume I: 59-80, Proceedings of the International Colloquium Riva del Garda (Trento, Italy), 11-16 May 1998. Provincia de Trento: Servizio Beni Culturali y Ufficio Beni Archeologici.

PARREIRA, R. (1983): O cerro dos Castelos da São Brás (Serpa). Relatório preliminar dos trabalhos arqueológicos de 1979 e 1980. O Arqueólogo Portugués, Serie IV, 1: 149-168. Lisboa.

- (1990): "Considerações sobre os milenios IV e III a.C. no Centro e Sul de Portugal", Estudos Orientais I: $27-43$.

PIRES, C. (1896): "Antas dos arredores de Machêde", O Archeólogo Português 2: 229-230. Lisboa.

SALANOVA, L. (1998): "Le statut des assemblages campaniformes en contexte funéraire : la notion de "bien de prestige", Bulletin de la Société Préhistorique Française 95 (3): 315-326.

- (2000): "Mecanismes de difusión des vases campaniformes: les liens franco-portugais", Actas do $3^{\circ}$ Congresso de Arqueologia Peninsular, vol IV. Pré-Historia Recente da Península Ibérica: 399- 409. Porto: ADECAP.

- (2000a): "Les sépultures mégalithiques et le phénoméne campaniforme, en V. Gonçalves (Ed.): ’Muita gente, poucas antas? Origens, espaços e contextos do Megalitismo" (Actas do II Colóquio Internacional sobre Megalitismo), Trabalhos de Arqueologia 25: 385-393. Lisboa: Instituto Português de Arqueolgia.

- (2001): "Technological, ideological or economic European union? The variability of bell beaker decoration", en F. Nicolis (eds.), Bell beakers today. Pottery, people, culture, symbols in prehistoric Europe, volume I: 91-102, Proceedings of the International Colloquium Riva del Garda (Trento, Italy), 11-16 May 1998. Provincia de Trento: Servizio Beni Culturali y Ufficio Beni Archeologici.

- (2004): "The frontiers inside the Western bell beaker block", en J. Czebreszuk (ed.), Similar but different: Bell beakers in Europe: 63-75. Poznan: Adam Mickiewicz University.

- (2005): "Los orígenes del campaniforme: Descomponer, analizar, cartografiar", en M.A. Rojo, R. Garrido y I. García (coords.), El campaniforme en la Península Ibérica y su contexto europeo: 7-18. Valladolid: Universidad de Valladolid.

SANGMEISTER, E. (1963): "La civilisation du vase campaniforme. Exposé sur la civilisation du vase campaniforme", en Les Civilisations atlantiques $d u$ Neolithique a L'Age du Fer. Actes du premier colloque Atlantique Brest: 25-55. Rennes.

- (1966): "Los vasos campaniformes portugueses en el marco de las culturas del vaso campaniforme europeo", Comemoraçao do Primero Centenario do Associaçao dos arqueólogos Portugueses 18631963, I: 203-216. Lisboa.

SCHMIDT, H. (1915): "Estudios acerca de los principios de la Edad de los Metales en España" (Traducido por Bosch-Gimpera del original de 1913), Memoria $n^{\circ} 8$ de la Comisión de Investigaciones Paleontológicas y Prehistóricas, Madrid: Museo de Ciencias Naturales.

SCHUBART, H. (1965): “As duas fases de ocupação do túmulo de cúpula do Monte do Outeiro, nos arredores de Aljustrel”, Gvimarães LXXV, 1-4: 195204.

— (1965b): "Zwei Belegungsphasen im Kuppelgrab Monte do Outeiro bei Aljustrel (Portugal) ", Madrider Mitteilungen 6: 65-73.

- (1971): "O Horizonte de Ferradeira. Sepulturas do Eneolítico final no Sudoeste da Península Ibérica”, Revista de Guimarães, t. LXXXI: 189-216.

SHERRATT, A. (1987): "Cups that cheered", en W. H. Waldren y R. C. Kennard (eds.), "Bell beakers of the Western Mediterranean. Definition, interpretation, theory and new site data", British Archaeological Reports, Int. Series, 331 (i): 81-114, Oxford. 
- (1991): "Sacred and profane substances: the ritual use of narcotics in later Neolithic Europe", en P. Garwood, D. Jennings, R. Skeates y J. Toms (eds.), Sacred and profane. Proceedings of a conference on archaeology, ritual and religion (Oxford 1989): 50-64, Oxford: Oxford University Committee for Archaeology, Monograph No. 32.

SIMÕES CORREIRA SERRALHEIRO, A. y FREIRE DE ANDRADE, R. (1961): “O monumento megalítico do Monte das Pereiras", Comunicaçoes dos Serviços Geológicos de Portugal XLV: 503-516.

SIRET, L. (1913): Questions de Chronologie et d'Ethnographie Ibériques, Tomo I. Paris: Paul Geuthner.

SOARES, J.; BARBIERI, N. y TAVARES DA SILVA, C. (1972): "Povoado calcolítico do Moinho da Fonte do Sol (Quinta do Anjo-Palmela)", Arqueologia e História, Série 9, vol. IV. Lisboa.

SOARES, J. y TAVARES DA SILVA, C. (1985): "Resumos de intervenções em Escoural (Montemos-o-Novo) e Monte da Tumba (Torrão) ", Clio Arqueología, Revista da Uniarch, Vol. 1: 77-79. Lisboa.

STRAHM, C. (1979): “Kalibration und die Herkunft der Glockenbecher", Archives Suisses d'Anthropologie Générale 43: 285-293.

SUÁREZ OTERO, J. (1997): “Cerámica campaniforme con decoración cordada en la península ibérica. Acotaciones en torno a una problemática", Boletín Avriense XXVI: 27-46.

SUÁREZ OTERO, J. y LESTÓN GÓMEZ, M. (2005): "Un vaso con decoración cordada en la Galicia y el problema de los orígenes de la cerámica campaniforme en el occidente ibérico", Madrider Mitteilungen 46: 1-21.

TAVARES DA SILVA, C. y SOARES, J. (1987): “O povoado fortificado calcolítico do Monte da Tumba.
I- Escavações arqueológicas de 1982-86 (Resultados priliminares) ", Setúbal Arqueológica VIII: 29-79.

- (2002): "Porto das Carretas. Um povoado calcolítico fortificado do vale do Guadiana”, Almadán, Série II, $\mathrm{n}^{\circ} 11: 176-180$.

THOMAS, J. (2005): “¿Ceremonias de los Jinetes? De las tumbas megalíticas a los enterramientos campaniformes en la Europa prehistórica", en M.A. Rojo, R. Garrido y I. García (Coord.): El campaniforme en la Península Ibérica y su contexto europeo: $107-$ 122. Valladolid: Universidad de Valladolid.

VALERA, A.C. (2000): "O Monte do Tosco I: Uma análise preliminar no contexto do povoamento calcolítico e do início da Idade do Bronze na margem”, Era-Arqueologia 2: 33-51. Lisboa.

- (2002): "Pré-História Recente da Margem Esquerda do Guadiana", Al-madán, Série II, 11: 117-121.

- (2006): “A margem esquerda do Guadiana (região de Mourão), dos finais do $4^{\circ}$ aos inícios do $2^{\circ}$ milênio AC. ", Era-arqueologia n ${ }^{\circ}$ 7: 136-210.

VALERA, A.C. y FILIPE, I. (2004): “O povoado de Porto Torrão (Ferreira do Alentejo). Novos dados e novas problemáticas no contexto da calcolitização do Sudoeste peninsular", Era-arqueologia n ${ }^{\circ}$ 6: 28-61.

VALERA, A.C. y otros (2000): “Ambientes funerarios no complexo arqueológico dos Perdigões: Uma análise preliminar no contexto das prácticas funerarias calcolíticas no Alentejo", Era-arqueologia n 2: 84-105.

VALERA GOMES, R.; VALERA GOMES, M. y FARINHA DOS SANTOS, M. (1983): “O Santuário exterior do Escoural. Sector NE (Montemor-o-Novo, Évora)", Zephyrvs XXXVI: 287-307.

VEIGA FERREIRA, O. da (1971): "Um escondrijo de fundidor encontrado no Castro de São Bernardo (Moura), Alentejo", O Arqueologo Portugués, Série III, vol. V : 139-145. 